\title{
Obscurin is required for ankyrinB-dependent dystrophin localization and sarcolemma integrity
}

\author{
Davide Randazzo, ${ }^{2}$ Emiliana Giacomello, ${ }^{1,2}$ Stefania Lorenzini, ${ }^{1}$ Daniela Rossi, ${ }^{1,2}$ Enrico Pierantozzi, \\ Bert Blaauw, ${ }^{2,3}$ Carlo Reggiani, ${ }^{2,3}$ Stephan Lange, ${ }^{4}$ Angela K. Peter, ${ }^{4}$ Ju Chen, ${ }^{4}$ and Vincenzo Sorrentino ${ }^{1,2}$ \\ 'Molecular Medicine Section, Department of Molecular and Developmental Medicine, and ${ }^{2}$ Interuniversitary Institute of Myology, University of Siena, 53100 Siena, Italy \\ ${ }^{3}$ Department of Biomedical Sciences, University of Padua, 35137 Padua, Italy \\ ${ }^{4}$ University of California, San Diego School of Medicine, La Jolla, CA 92093
}

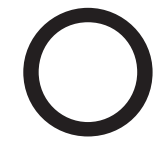
bscurin is a large myofibrillar protein that contains several interacting modules, one of which mediates binding to muscle-specific ankyrins. Interaction between obscurin and the muscle-specific ankyrin sAnk 1.5 regulates the organization of the sarcoplasmic reticulum in striated muscles. Additional musclespecific ankyrin isoforms, ankB and ankG, are localized at the subsarcolemma level, at which they contribute to the organization of dystrophin and $\beta$-dystroglycan at costameres. In this paper, we report that in mice deficient for obscurin, ankB was displaced from its localization at the $M$ band, whereas localization of ankG at the $Z$ disk was not affected. In obscurin $\mathrm{KO}$ mice, localization at costameres of dystrophin, but not of $\beta$-dystroglycan, was altered, and the subsarcolemma microtubule cytoskeleton was disrupted. In addition, these mutant mice displayed marked sarcolemmal fragility and reduced muscle exercise tolerance. Altogether, the results support a model in which obscurin, by targeting ankB at the $M$ band, contributes to the organization of subsarcolemma microtubules, localization of dystrophin at costameres, and maintenance of sarcolemmal integrity.

\section{Introduction}

Obscurin is a giant scaffold protein present in striated muscles initially identified on the basis of its ability to bind titin (Young et al., 2001; Kontrogianni-Konstantopoulos et al., 2009). The structural layout of obscurin is based on in-tandem arrangements of adhesion and signaling domains that include intracellular immunoglobulin and fibronectin III-like domains, an IQ motif, an SH3 (src homology 3) domain, a RhoGEF (double homology domain), and a pleckstrin homology motif. In adult skeletal muscles, the predominant isoform, obscurin A, is characterized by a nonmodular region of 420 aa residues bearing several putative extracellular signaling-regulated kinase phosphorylation sites (Young et al., 2001). In a second isoform of higher molecular weight, obscurin $\mathrm{B}$, the nonmodular C-terminal sequence is replaced by two serine/threonine kinase-like domains (Russell et al., 2002; Fukuzawa et al., 2005). In addition, two other smaller variants consisting only of the kinase domains (tandem myosin light chain kinase and skeletal myosin light

Correspondence to Vincenzo Sorrentino: vincenzo.sorrentino@unisi.it

Abbreviations used in this paper: DGC, dystrophin-glycoprotein complex; EBD Evans blue dye; $E D L$, extensor digitorum longus; FDB, flexor digitorum brevis; $\mathrm{KO}$, knockout; OBD, obscurin-binding domain; PVDF, polyvinylidene fluoride; $\mathrm{SBD}$, spectrin-binding domain; $\mathrm{SR}$, sarcoplasmic reticulum. chain kinase) have been characterized (Bowman et al., 2007). Given the modular architecture consisting of structural and signaling domains, obscurin is involved in several interactions that are important for the organization of contractile proteins in the sarcomere (Clark et al., 2002). Indeed, obscurin participates in the M-band assembly via interactions with titin and myomesin (Fukuzawa et al., 2008). Finally, the RhoGEF domain of obscurin mediates direct binding to RANBP-9 and is involved in the activation of small GTPase proteins, such as RhoA and RhoQ/TC10 (Bowman et al., 2008; Coisy-Quivy et al., 2009; Ford-Speelman et al., 2009).

In addition to sarcomeric proteins, obscurin can interact with some isoforms of ankyrin proteins (Bagnato et al., 2003; Kontrogianni-Konstantopoulos et al., 2003; Armani et al., 2006; Borzok et al., 2007; Cunha and Mohler, 2008). Ankyrins are versatile adaptor proteins that coordinate the assembly of a molecular "bridge" between integral membrane proteins and the spectrin-based cytoskeleton, thereby promoting the assembly of

(C) 2013 Randazzo et al. This article is distributed under the terms of an AttributionNoncommercial-Share Alike-No Mirror Sites license for the first six months after the publication date (see http://www.rupress.org/terms). After six months it is available under a Creative Commons License (Attribution-Noncommercial-Share Alike 3.0 Unported license, as described at http://creativecommons.org/licenses/by-nc-sa/3.0/). 
protein complexes at specific regions of the plasma membrane (Bennett and Baines, 2001; Bennett and Healy, 2009; Cunha and Mohler, 2011). In vertebrates, three genes (ank1, ank2, and ank3, which encode proteins named ankR, ankB, and ankG, respectively) generate multiple isoforms, expressed in a tissuespecific manner and classified according to their size as giants (480-270 kD), canonical (220-190 kD), and small ankyrins (20 kD; Bennett and Baines, 2001). Ankyrins have a complex molecular structure consisting of a membrane-binding domain that mediates the interaction with the cytoplasmic region of trans-membrane proteins, a spectrin-binding domain (SBD) that connects to the cytoskeleton, and two additional regions, the death domain and the C-terminal regulatory domain (Bennett and Baines, 2001). A low molecular weight isoform encoded by the ank1 gene, sAnk1.5 (or small ank1), contains an N-terminal trans-membrane sequence that embeds this protein within the sarcoplasmic reticulum (SR) membrane (Zhou et al., 1997). The cytoplasmic region of sAnk1.5 contains an amino acid sequence that is able to mediate the interaction with the $\mathrm{C}$-terminal region of obscurin (Bagnato et al., 2003; Kontrogianni-Konstantopoulos et al., 2003; Armani et al., 2006). In striated muscles, sAnk1.5 colocalizes with obscurin. Both proteins are observed predominantly in correspondence of the $\mathrm{M}$ band but can be also found at lower levels in close proximity to the $\mathrm{Z}$ disk (Giacomello and Sorrentino, 2009). Site-directed mutagenesis of the specific amino acid residues in sAnk1.5 that are required for interaction with obscurin impaired the ability of sAnk1.5 to localize to the M band in cultured muscle cells (Bagnato et al., 2003; Cusimano et al., 2009). In addition, siRNA-induced knockdown of obscurin altered the organization of SR in C2C12 cells (KontrogianniKonstantopoulos et al., 2006; Ackermann et al., 2011). Accordingly, in an obscurin knockout (KO) mouse model, sAnk1.5 was mislocalized to the $\mathrm{Z}$ disk, and the overall architecture of the longitudinal SR, but not that of the junctional SR, was altered (Lange et al., 2009). These results agree with a model in which the interaction between obscurin and sAnk1.5 is necessary for tethering the SR to the contractile apparatus (Rossi et al., 2008; Sorrentino, 2011). Further observations have shown that a 76-aa sequence, bearing two obscurin-binding domains (OBDs), is present in almost all ankyrin isoforms expressed in striated muscles (Bagnato et al., 2003; Hopitzan et al., 2005). In cardiac myocytes, the $220-\mathrm{kD}$ muscle-specific isoform ankB, encoded by the ank2 gene, plays a role in the assembly of $\mathrm{Na} / \mathrm{K}$ ATPase, $\mathrm{Na} / \mathrm{Ca}$ exchanger, and inositol trisphosphate receptor proteins in specialized microdomains involved in the regulation of intracellular calcium homeostasis at $\mathrm{t}$ (transverse) tubules (Mohler et al., 2005). Cardiac myocytes express two ankB splice variants containing one or two OBDs that, by interacting with obscurin, target the phosphatase A2 protein to the M-band region of the sarcomere (Cunha and Mohler, 2008). In skeletal muscle, six ankG isoforms, encoded by the ank3 gene, all containing the two OBDs, are also expressed and shown to localize at the subsarcolemma level in alignment with the $\mathrm{Z}$ disk (Gagelin et al., 2002; Hopitzan et al., 2005). Furthermore, Maiweilidan et al. (2011) reported that the very same 76 aa residues that bind obscurin can also interact with the cytoskeletal proteins plectin and filamin $\mathrm{C}$.
More recently, two muscle-specific ankyrin isoforms, ankB and ankG, have been shown to have a key role in the organization of dystrophin and $\beta$-dystroglycan at costameres and at neuromuscular junctions in skeletal muscles fibers (Ayalon et al., 2008, 2011). Dystrophin and $\beta$-dystroglycan participate in the assembly of the dystrophin-glycoprotein complex (DGC), containing integral membrane components (sarcospan, $\alpha-, \beta-, \gamma-$, and $\delta$-sarcoglycans, and $\beta$-dystroglycan) and peripheral membrane proteins ( $\alpha$-dystroglycan, $\alpha 1 / \beta 1$-syntrophins, and dystrophin; Crosbie et al., 1997; Ervasti, 2003). The DGC represents the structural core of the costameres, which are specialized membrane domains formed at the junction between the sarcolemma and the $\mathrm{Z}$ disk of peripheral myofibrils (Pardo et al., 1983). Evidence of costamere-like protein assemblies in register with the $\mathrm{M}$ bands has been also reported; however, their composition and function remain poorly understood (Nelson and Lazarides, 1983). The membrane-spanning DGC confers stability to the sarcolemma linking the subcortical cytoskeleton to the ECM, therefore acting as a force-buffering system that prevents structural damage during contraction (Danowski et al., 1992; Ervasti, 2003). Indeed, the N-terminal region of dystrophin is able to bind subsarcolemmal $\gamma$-actin (Prins et al., 2008) and $\alpha$-tubulin (Prins et al., 2009). Other components of the DGC are stably connected to intermediate filament-associated proteins: $\alpha$-dystrobrevin and $\beta$-dystroglycan are directly linked to plectin-1 and -1F (Rezniczek et al., 2007; Hijikata et al., 2008), whereas $\gamma$ - and $\delta$-sarcoglycans interact with filamin $C$ (Thompson et al., 2000). Notably, in the Duchenne muscular dystrophy, mutations in the dystrophin gene affect DGC stability, resulting in sarcolemma fragility and hence muscle degeneration (Hoffman et al., 1987).

Ayalon et al. (2008) used gene silencing techniques to demonstrate that lack of ankB prevented localization of dystrophin and $\beta$-dystroglycan to the sarcolemma, whereas ankG was necessary for their localization at costameres and for maintenance of sarcolemma integrity. In particular, ankB, which is recruited to $\mathrm{Z}$ disks by $\beta 2$-spectrin, is necessary for proper delivery of dystrophin and $\beta$-dystroglycan to the sarcolemma through direct binding to dynactin- 4 , a microtubule-associated protein that is responsible for the assembly of a specific set of subsarcolemmal microtubules (Ayalon et al., 2008). These authors proposed a hierarchical model, in which the organization of a functional DGC at the costamere level starts with the recruitment of ankB by the cytoskeletal protein $\beta 2$-spectrin. AnkB in turn, interacts with both dystrophin and dynactin- 4 to coordinate the correct delivery of dystrophin and $\beta$-dystroglycan through the subsarcolemma microtubule cytoskeleton (Ayalon et al., 2011).

Given that the organization of costameres depends on multiple interactions and that all muscle-specific ankyrin isoforms contain OBDs, we raised the question whether obscurin may also contribute to the assembly of dystrophin and $\beta$-dystroglycan at costameres. Our results indicate that localization of ankB, but not ankG, requires the expression of obscurin. Moreover, deletion of obscurin altered the localization of dystrophin at costameres and the organization of costamere-associated microtubules and was accompanied by sarcolemma fragility after exercise. 


\section{Results}

Localization of ankB, but not of ankG, is lost in skeletal muscle fibers of obscurin KO mice

Confocal microscopy imaging along the longitudinal axis of flexor digitorum brevis (FDB) fibers from adult control mice showed that obscurin and ankB have an identical localization pattern. Major staining of both proteins alternated with that obtained with an antibody against the Z-disk protein $\alpha$-actinin and was therefore compatible with M-band localization. However, a weaker decoration was also detectable at the Z-disk level (Fig. 1, A, B, D, E, G, and H). Conversely, the ankG protein was predominantly aligned in correspondence of the $\mathrm{Z}$ disk (Fig. 1, C, $\mathrm{F}$, and I). In cross sections of the tibialis anterior muscle, obscurin, ankB, and ankG were localized at the subsarcolemma level (Fig. 1, J-L), as also reported in human striated muscles (Carlsson et al., 2008). However, although the obscurin signal was also evident in the interior part of muscle fibers, ankB and ankG staining yielded a clear signal at the subsarcolemma level. To verify whether obscurin is required for localization of ankB and ankG proteins in mouse skeletal muscle, we used a previously described obscurin KO mouse model (Lange et al., 2009). Immunostaining of skeletal muscle fibers from FDB muscle of control and obscurin $\mathrm{KO}$ mice revealed that the typical localization pattern of ankB at the $\mathrm{M}$ band was lost in obscurin $\mathrm{KO}$ mice skeletal muscle fibers, with most of the ankB immunofluorescence signal yielding an apparently nonorganized distribution (compare Fig. 2, B and E). It is worth noting that, in skeletal muscle fibers from obscurin $\mathrm{KO}$ mice, a minor fraction of ankB staining was also detectable at the $\mathrm{Z}$ disk (Fig. $2 \mathrm{H}$ ). On the contrary, the localization pattern of ankG was similar in skeletal muscle fibers from control and obscurin $\mathrm{KO}$ mice (Fig. 2, C, $\mathrm{F}$, and I). Altogether, these data indicate that obscurin is required for localization of ankB, but not of ankG, in skeletal muscle fibers. To test the possibility that obscurin and ankB may associate in skeletal muscle fibers, immunoprecipitation experiments were performed with solubilized proteins from skeletal muscle lysates using an antibody against the $\mathrm{C}$-terminal region of obscurin. As shown in Fig. $2 \mathrm{~J}$, ankB, but not ankG, was coimmunoprecipitated in skeletal muscle lysates from control mice, in agreement with previous data obtained in cardiac muscle (Cunha and Mohler, 2008). Under these experimental conditions, sAnk1.5 was also coimmunoprecipitated with obscurin. In contrast, ankB and sAnk1.5 were not coimmunoprecipitated in skeletal muscle lysates from obscurin $\mathrm{KO}$ mice. The interaction between obscurin and ankB and sAnk1.5 was confirmed by GST pull-down experiments (Fig. 2 K) using skeletal muscle lysates from control mice and a GST fusion protein (A7VI) containing the $\mathrm{C}$-terminal region of obscurin encompassing the ankyrin binding sites (Armani et al., 2006).

Targeting of ankB to the $M$ band requires the presence of OBDs

Next, we asked whether M-band localization of ankB in mouse skeletal muscle fibers was dependent on the two OBDs in the $\mathrm{C}$ terminus of ankB. Plasmids encoding GFP-tagged ankB protein
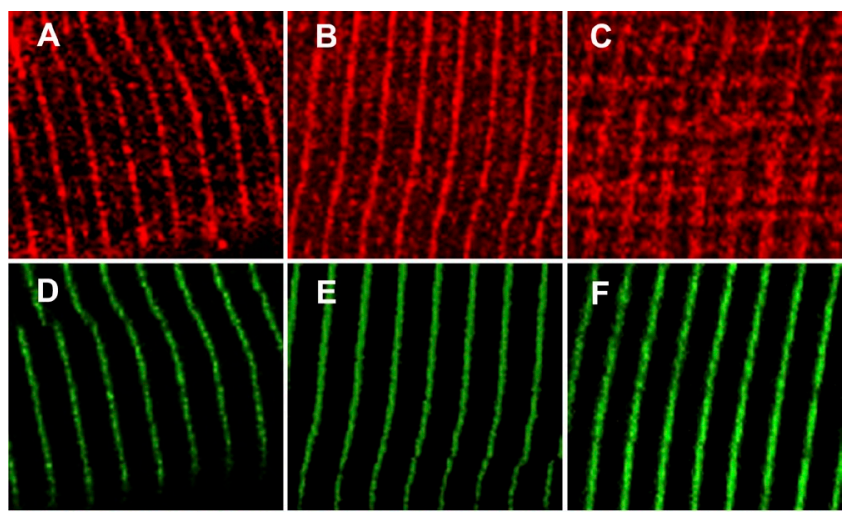
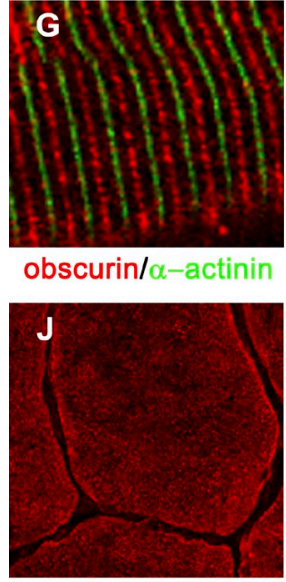

obscurin

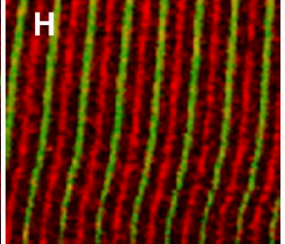

ankB/ $\alpha$-actinin

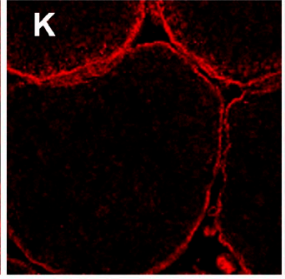

ankB

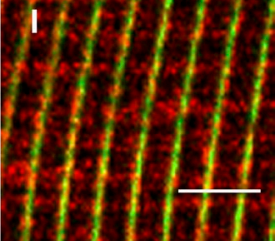

ankG/ $\alpha$-actinin

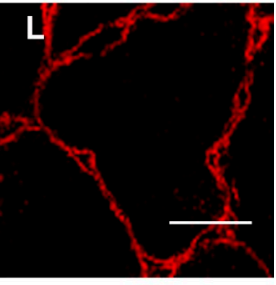

ankG
Figure 1. Localization of obscurin, ankB, and ankG in control skeletal muscle fibers. (A-I) Immunostaining of FDB fibers from control mice shows colocalization of obscurin $(A, D$, and $G)$ and $\operatorname{ankB}(B, E$, and $H)$ at the $M$ band. Conversely, ankG (C, F, and I) is predominantly localized in coincidence to the $Z$ disk. $\alpha$-Actinin is used to mark the $Z$ disks. Bar, $5 \mu \mathrm{m}$. $(\mathrm{J}-\mathrm{L})$ Analysis of tibialis anterior cross sections shows obscurin (J), ankB (K), and ankG (L) localized at the subsarcolemmal region. Bar, $20 \mu \mathrm{m}$.

(GFP-ankB) or GFP-ankB mutant proteins lacking two (GFPankB- $\Delta$ OBD1/2) or either one of the OBDs (GFP-ankB- $\Delta$ OBD1 and GFP-ankB- $\Delta$ OBD2) were prepared (Fig. 3 A and Fig. S1 A). These plasmids were in vivo electroporated into FDB muscles of control and obscurin $\mathrm{KO}$ mice, and confocal microscopy analysis was performed $8 \mathrm{~d}$ after electroporation. As expected, the GFP-ankB protein signal in control fibers was distinct from that obtained with an antibody against $\alpha$-actinin yielding a localization pattern at the M-band region (Fig. 3, B, D, and F). In contrast, the GFP-ankB protein colocalized with $\alpha$-actinin at $\mathrm{Z}$ disks in obscurin $\mathrm{KO}$ animals (Fig. 3, C, E, and G), with GFP-ankB displaying a significantly wider signal than that observed with the antibody against $\alpha$-actinin. Conversely, the GFP-ankB- $\triangle$ OBD1 mutant showed a diffuse signal around the $\mathrm{Z}$ disk, both in skeletal muscle fibers from control and obscurin KO mice (Fig. 3, H-M). Similar results were observed with GFPankB mutants lacking OBD2 (GFP-ankB $\Delta \mathrm{OBD} 2)$ or both OBD1 and OBD2 (GFP-ankB $\Delta$ OBD1/2; Fig. S1, B-M). Reported evidence has shown that association of ankB to costameres in correspondence to $\mathrm{Z}$ disks requires the direct interaction of ankB with $\beta 2$-spectrin (Ayalon et al., 2011). FDB muscle fibers from control, obscurin $\mathrm{KO}$, and mdx mice were stained with an 
Figure 2. Localization of ankB is altered in skeletal muscle fibers of obscurin $\mathrm{KO}$ mice. (A-I) Comparison of obscurin $(A, D$, and $G)$, ankB $(B, E$, and $H)$, and ankG $(C, F$, and $I)$ localization between control and $\mathrm{KO}$ mice reveals that, in absence of obscurin, ankB localization at the $M$ band is lost, whereas a fuzzy localization $(E)$ or a weak alignment at the $Z$ disk $(H)$ remain. AnkG is unaffected in obscurin $\mathrm{KO}$ fibers ( $F$ and I). $\alpha$-Actinin marks $Z$ disks as shown in the merged images reported in the insets. Bar, $10 \mu \mathrm{m}$. (J and $K$ ) In vivo and in vitro interactions of obscurin with ankB and sAnk 1.5. (J) AnkB and sAnk 1.5 were coimmunoprecipitated with an antibody against obscurin from skeletal muscle lysates of control mice (third lane) but not from those of obscurin KO mice (sixth lane). No band was detected with an unrelated antibody (second lane). Arrowhead indicates the band corresponding to sAnk 1.5 (K) GST pull-down assays. GST fusion protein A7VI, containing the C-terminal region of obscurin (aa 6,215-6,353) was used to pull down ankB and sAnk1.5 from skeletal muscle ly sates. First lane shows $10 \mu$ l of total muscle lysate; second lane shows proteins pulled down with GST-A7VI; third lane shows proteins pulled down with GST as a control. IB, immunoblot.
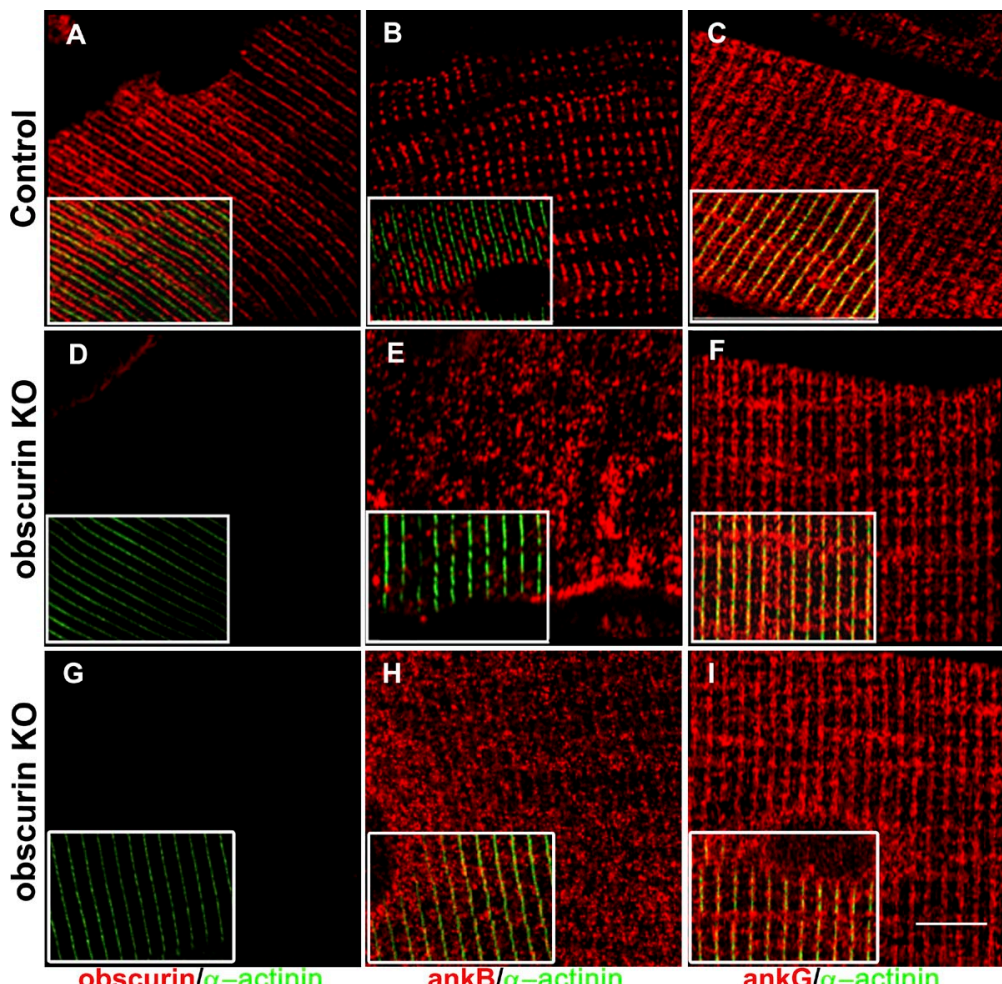

obscurin/ $\alpha$-actinin

ankB/a-actinin

ankG/a-actinin

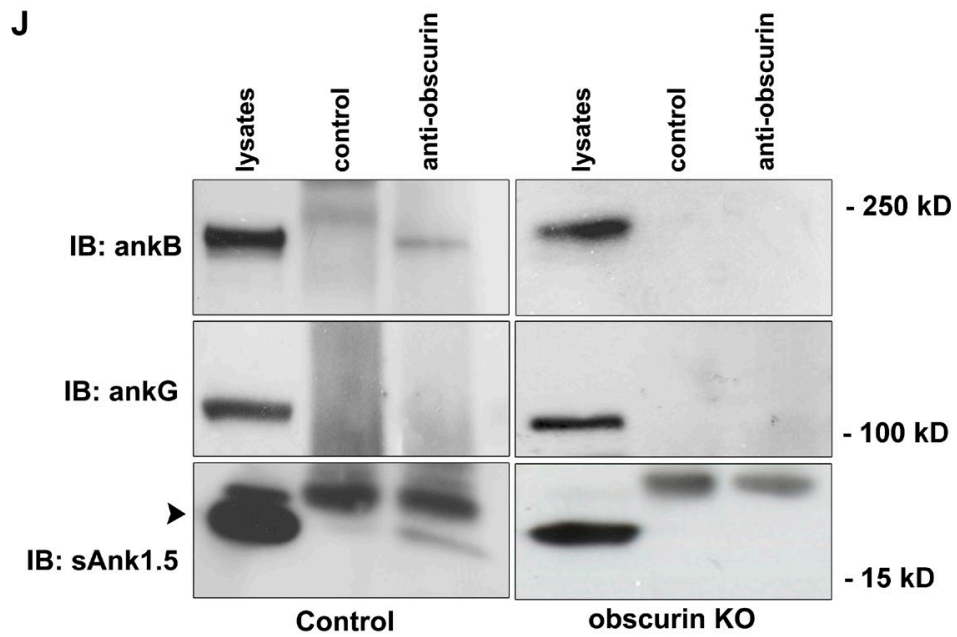

K

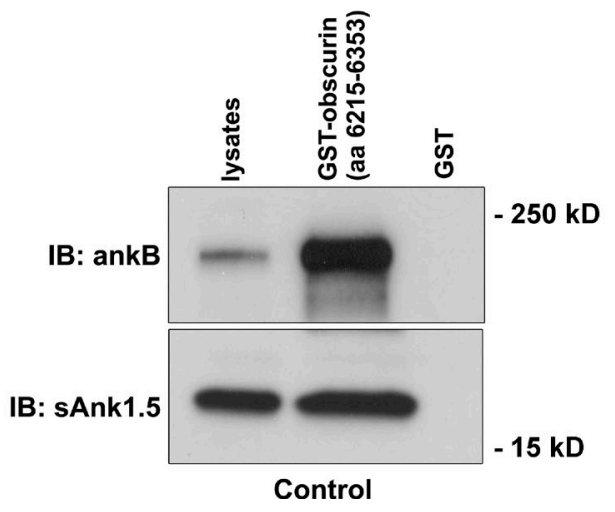


antibody against $\beta 2$-spectrin. As previously described (Nelson and Lazarides, 1983; Ayalon et al., 2008), $\beta 2$-spectrin appeared as a gridlike network underneath the sarcolemma with a predominant staining in correspondence to the $\mathrm{Z}$ disk and, to a lesser degree, at the $\mathrm{M}$ band of control and obscurin $\mathrm{KO}$ mice (Fig. S2, A, B, D, E, G, and H). In contrast, the $\beta 2$-spectrin localization pattern in FDB muscle fibers from mdx mice revealed a reduced staining at the $\mathrm{M}$ band, whereas staining at the $\mathrm{Z}$ disk was not affected (Fig. S2, C, F, and I). This finding is in agreement with previously reported localizations of $\beta$-spectrin in $\mathrm{mdx}$ mice by Williams and Bloch (1999). We therefore prepared a mutant GFP-tagged ankB protein (GFP-ankB- $\Delta$ SBD) lacking aa 966-1,125 that contains the ZU5 domain + 55 aa that corresponds to the minimal SBD in ankB (Mohler et al., 2004). In addition, a construct deleted of the SBD and of the two OBDs (GFP-ankB- $\Delta$ SBD- $\Delta$ OBD1/2) was prepared (Fig. 4 A). After electroporation of the GFP-ankB- $\Delta$ SBD plasmid into FDB muscle, the fluorescence signal was observed at the $\mathrm{M}$ band in skeletal muscle fibers from control mice (Fig. 4, B, D, and F), whereas in fibers from obscurin $\mathrm{KO}$ mice, only a residual staining around the Z-disk region was observed (Fig. 4, C, E, and G). Electroporation of the FDB muscle with the GFP-ankB mutant lacking the SBD and both OBDs yielded only a fuzzy signal over the $\mathrm{Z}$ disks in skeletal muscle fibers from control mice and an even more disorganized staining in those from obscurin $\mathrm{KO}$ mice (Fig. 4, H-M). To confirm these observations, we prepared two GFP fusion proteins, one containing only the minimal SBD amino acid sequence (GFP-SBD) and one containing only the two OBD amino acid sequences (GFP-OBD1+2) of ankB (Fig. S3, A and B). Electroporation of these two constructs into the FDB muscle of control mice indicated that the GFP-SBD fusion protein was localized at the $\mathrm{Z}$ disk, whereas the GFPOBD1+2 fusion protein was localized at the M band, thus reflecting the ability of these two domains to establish specific direct interactions with $\beta 2$-spectrin and obscurin, respectively (Fig. S3, C-H). Altogether, our results indicate that ankB protein localization at the $\mathrm{M}$ band relies on the interaction with obscurin. As a consequence, lack of obscurin as well as the altered binding capacity determined by the absence of one or both OBDs, restricts the ankB localization at the Z-disk level, at which localization may require the SBD to interact with $\beta 2$-spectrin. Whether the smaller fraction of obscurin localized at the $\mathrm{Z}$ disk contributes to localization of ankB to this site remains unclear, but it is certainly less evident than the contribution of $\beta 2$-spectrin.

\section{Ablation of obscurin alters the localization of dystrophin but not of $\beta$-dystroglycan and sarcoglycans at costameres and impairs the correct assembly of the subsarcolemma microtubule cytoskeleton} AnkB and ankG have recently been shown to be required for the localization of dystrophin and $\beta$-dystroglycan at costameres (Ayalon et al., 2008). We therefore wanted to verify whether the observed mislocalization of ankB in obscurin $\mathrm{KO}$ mice could affect dystrophin and/or $\beta$-dystroglycan organization. Surprisingly, immunostaining of FDB muscle fibers from control and
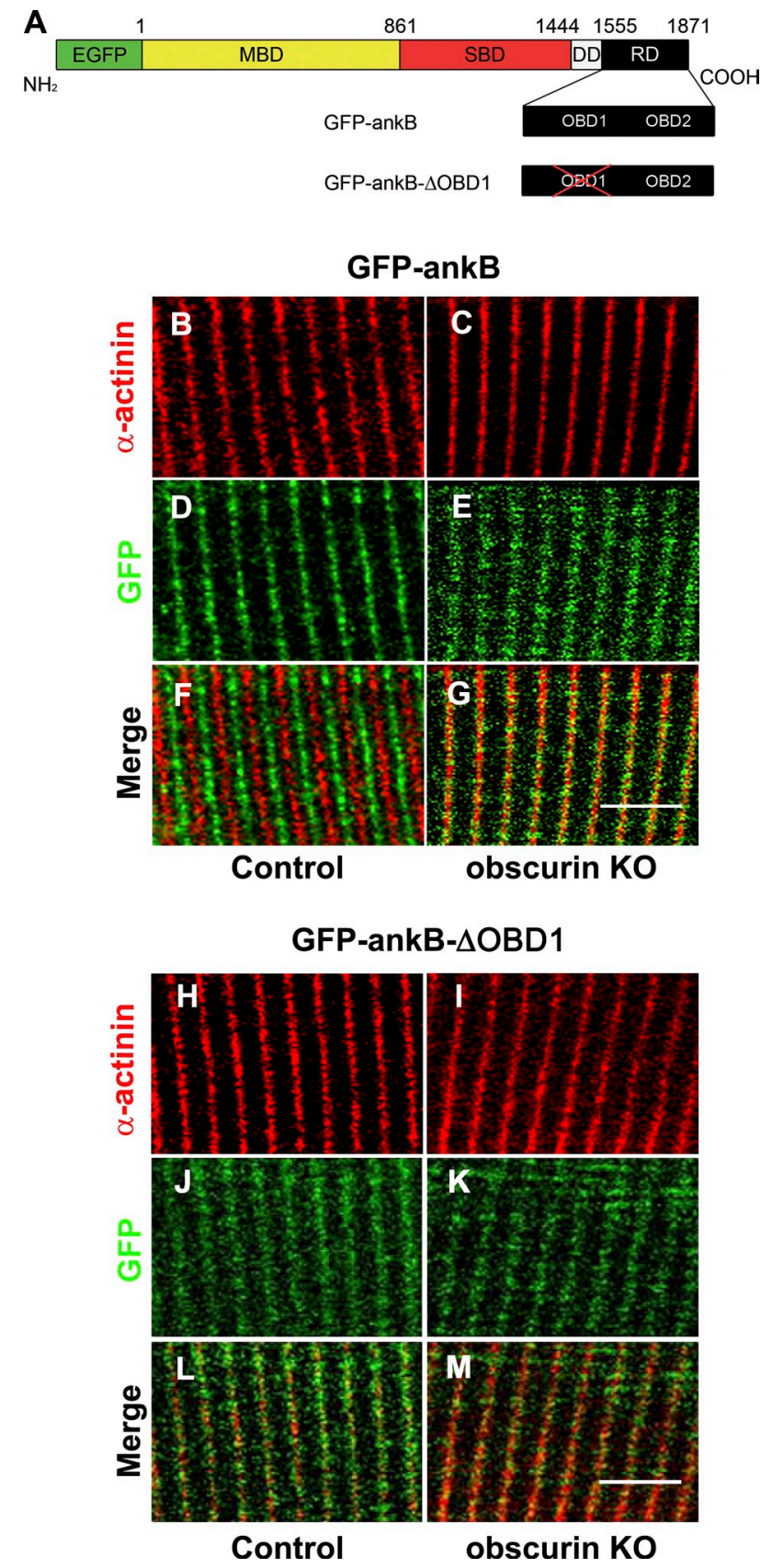

Figure 3. The two OBDs in ankB are necessary for localization at the $M$ band in skeletal muscle. (A) Schematic representation of GFP-tagged constructs used for in vivo electroporation of FDB muscles of control and obscurin $K O$ mice $(M B D$, membrane-binding domain; SBD, spectrin-binding domain; $\mathrm{DD}$, death domain; $\mathrm{RD}$, regulatory domain containing the two OBD sites). (B-G) The construct containing two OBDs (GFP-ankB) localizes at the $M$ band $(B, D$, and $F)$ in control fibers, whereas in obscurin $K O$ fibers, the staining is observed at the $Z$ disk $(C, E$, and $G)$. $(H-M)$ The construct lacking OBDI (GFP-ankB- $\triangle O B D 1$ ) displays a fuzzy localization in coincidence with $\mathrm{Z}$ disks both in control $(\mathrm{H}, \mathrm{J}$, and $\mathrm{L})$ and obscurin $\mathrm{KO}$ fibers $(\mathrm{I}, \mathrm{K}$, and $\mathrm{M})$. $\alpha$-Actinin is used to mark $Z$ disks. Bars, $5 \mu \mathrm{m}$.

obscurin $\mathrm{KO}$ mice revealed that subsarcolemma localization of dystrophin was markedly reduced in obscurin $\mathrm{KO}$ muscle fibers, although a residual dystrophin staining at costameres could still be observed (Fig. 5, A and D). The dystrophin expression in fibers from skeletal muscles of obscurin $\mathrm{KO}$ and control mice stained with the MANDRA1 monoclonal antibody 
A
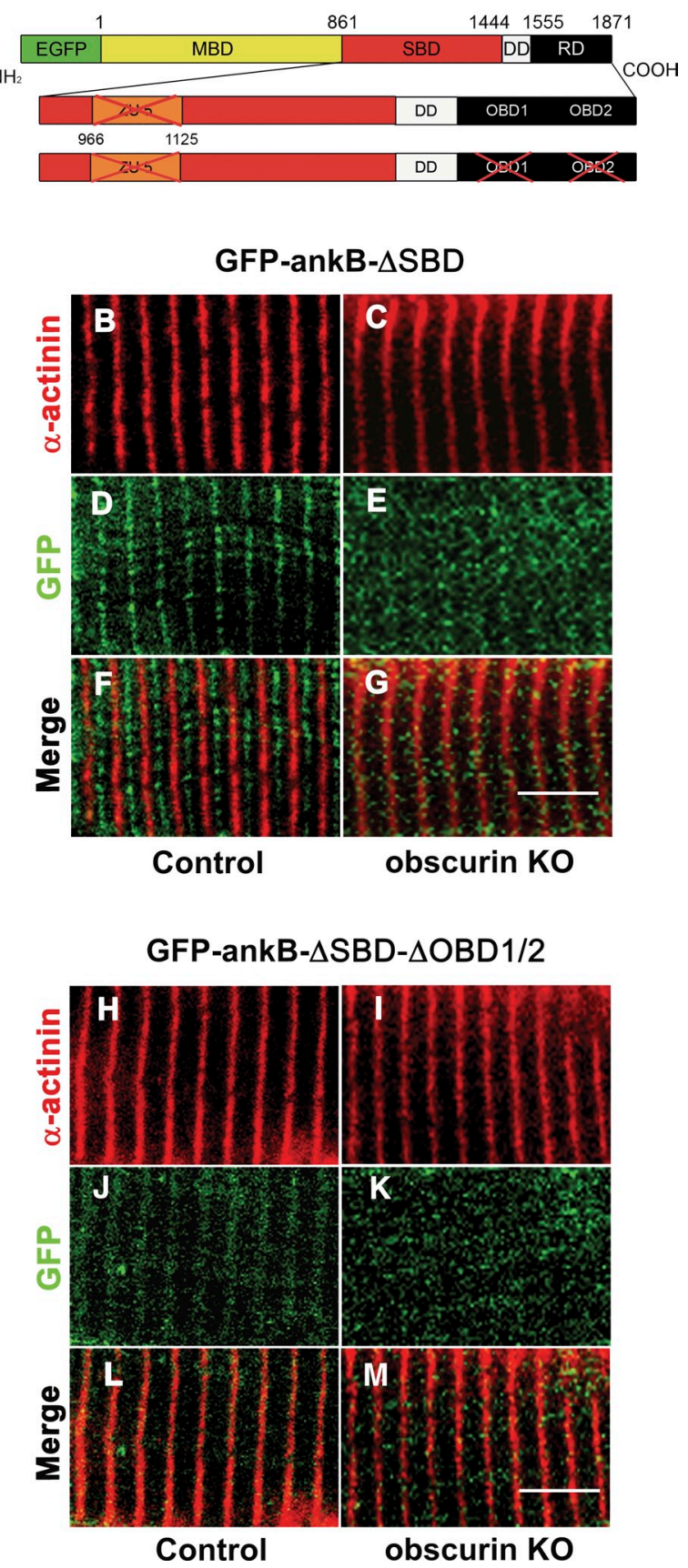

Figure 4. The SBD is necessary for ankB localization in the alignment to $Z$ disks. (A) Schematic representation of GFP-tagged ankB mutants lacking either only the amino acid residues $(966-1,125)$, corresponding to the minimal spectrin-binding domain $(S B D)$ or the SBD and both OBDs used for in vivo electroporations of FDB muscles $(M B D$, membrane-binding domain; ZU5 domain, domain found in ZO-1 and Unc-5-like netrin receptor 5; $D D$, death domain; RD, regulatory domain containing the two $O B D$ sites). (B-G) The ankB mutant lacking the SBD (GFP-ankB- $\triangle$ SBD) localizes at the $M$ band $(B, D$, and $F)$ in control but not in obscurin $K O$ fibers $(C, E$, and $G)$ where its localization is diffused. (H-M) The mutant lacking SBD and both OBDs (GFP-ankB- $\triangle$ SBD- $\triangle O B D 1 / 2$ ) shows a diffuse localization both in control $(\mathrm{H}, \mathrm{J}$, and $\mathrm{L})$ and obscurin $\mathrm{KO}$ muscle fibers $(\mathrm{I}, \mathrm{K}$, and $\mathrm{M})$. $\alpha$-Actinin is used to mark $Z$ disks. Bars, $5 \mu \mathrm{m}$.

against dystrophin was analyzed using ImageJ software (National Institutes of Health). Image analysis revealed that the dystrophin signal in fibers from obscurin KO muscle was decreased by $62.12 \pm 15 \%$ compared with that detected in control mice (299.00 \pm 119 and $789.25 \pm 433$ arbitrary units, respectively, $n=40 ; \mathrm{P}<0.001)$. In contrast, no difference was observed in the intensity of the staining nor in the localization pattern of $\beta$-dystroglycan (Fig. 5, B and E). Additional immunostaining experiments aimed to verify the localization of $\alpha-, \beta-, \gamma-$, and $\delta$-sarcoglycans (Fig. S4, A-H), $\gamma$-actin (Fig. S4, I and K), and $\beta 1 \mathrm{D}$-integrin (Fig. S4, J and L) revealed no alteration in the localization of these proteins at costameres/Z disks in skeletal muscle fibers of obscurin KO mice. Nevertheless, $\alpha$-tubulin immunostaining of FDB fibers of obscurin KO mice revealed an aberrant distribution of the subsarcolemmal microtubules (Fig. 5, C and F). These results agree with the data obtained by Ayalon et al. (2008) and with recent findings from a study of dystrophin-deficient mdx mice, in which the costamere-associated microtubule cytoskeleton is disrupted (Prins et al., 2009). The reduced dystrophin localization at the subsarcolemma in skeletal muscles was also confirmed in tibialis anterior cross sections, where the sarcolemma was visualized by Alexa Fluor 488-conjugated WGA staining (Fig. S5, A-F). No effects were observed, in obscurin $\mathrm{KO}$ muscle fibers, on the localization of other membrane proteins, including dihydropyridine receptor on t tubules, caveolin-3 at the sarcolemma, and ryanodine receptor type 1 at the SR, confirming the specificity of the effect determined by the lack of obscurin on dystrophin localization (Fig. 5, G-L). Interestingly, Western blot analysis on total protein lysates from tibialis anterior, extensor digitorum longus (EDL), and soleus muscles revealed comparable expression levels of ankB and dystrophin in control and obscurin KO mice (Fig. S5 G) as also reported by Ayalon et al. (2008) in skeletal muscle fiber knockdown for ankB. To investigate the discrepancy between the observed reduction in dystrophin levels from the sarcolemma of obscurin KO muscles and the unaltered dystrophin protein levels, we analyzed soluble protein fractions from control and obscurin KO muscles on sucrose gradients. In control muscle, dystrophin and other components of the DGC formed a tightly bound complex enriched in fractions $3-5$, in which $84.61 \pm 9.56 \%$ of the dystrophin protein was present (Fig. 6, A-D). In contrast, in obscurin KO muscles, only $38.00 \pm 5.65 \%$ of total dystrophin was associated with other core components of the DGC in fractions 3-5, whereas the remaining dystrophin was detected in fractions 7-13 (Fig. 6 A). Intriguingly, $\beta$-dystroglycan, $\alpha$-sarcoglycan, and $\gamma$-sarcoglycan were still found only in fractions 3-5 of the gradients of obscurin KO muscles (Fig. 6, $\mathrm{C}-\mathrm{H})$. Additionally, the redistribution of dystrophin in obscurin $\mathrm{KO}$ mice was not associated with other membrane components, such as caveolin- 1 and -3 and $\beta 1 \mathrm{D}$-integrin (Fig. 6, I-N), when compared with control muscles. In summary, muscles from obscurin $\mathrm{KO}$ mice display a characteristic reduction of dystrophin from the sarcolemma-bound DGC in immunofluorescence images, without an apparent effect on other DGC components. Biochemical analysis of DGC components further revealed that dystrophin was redistributed in obscurin $\mathrm{KO}$ muscles from the buoyant high molecular weight DGC fractions to lower molecular weight complexes that may represent non-membrane-associated proteins. 

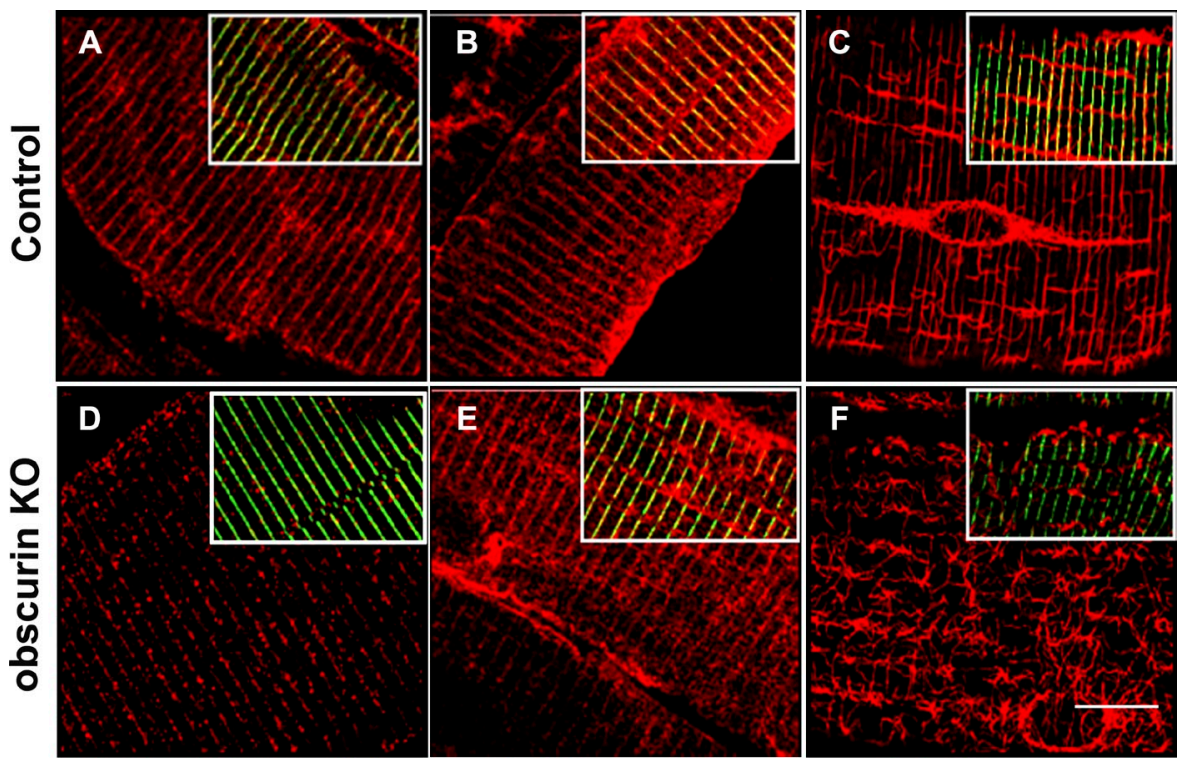

dystrophin/ $\alpha-$ actinin

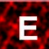

E
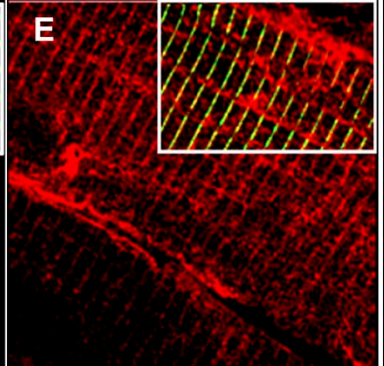

$\beta-\mathrm{DG} / \alpha-$ actinin

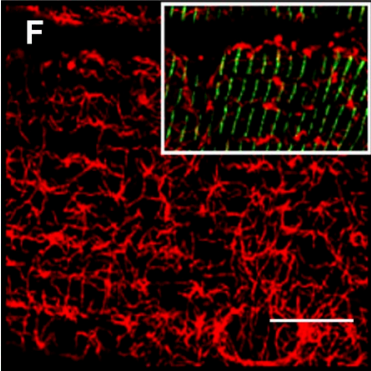

$\alpha$-tubulin/ $\alpha$-actinin

Figure 5. Localization of dystrophin at costameres and the organization of the microtubule cytoskeleton are impaired in skeletal muscle fibers of obscurin KO mice. (A and D) Immunostaining of whole FDB fibers reveals that dystrophin localization at costameres in obscurin $\mathrm{KO}$ muscle fibers (D) is markedly reduced compared with control (A). (B and $E$ ) Localization of $\beta$-dystroglycan ( $\beta$-DG) appears unchanged. ( $C$ and $F$ ) The assembly of the subsarcolemma microtubule cytoskeleton is impaired in obscurin KO mice. (G-L) The lack of obscurin does not alter the localization of membrane-bound proteins as revealed by immunostaining for the dihydropyridine receptor (DHPR; G and J), RyR-1 (H and K), and caveolin-3 (I and $L$ ). $\alpha$-Actinin is used to mark $Z$ disks as shown in the merged images reported in the insets. Bars, $10 \mu \mathrm{m}$.
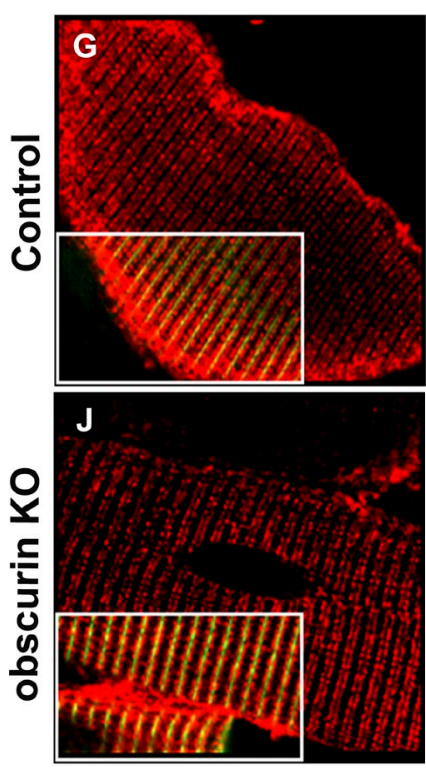

DHPR/a-actinin
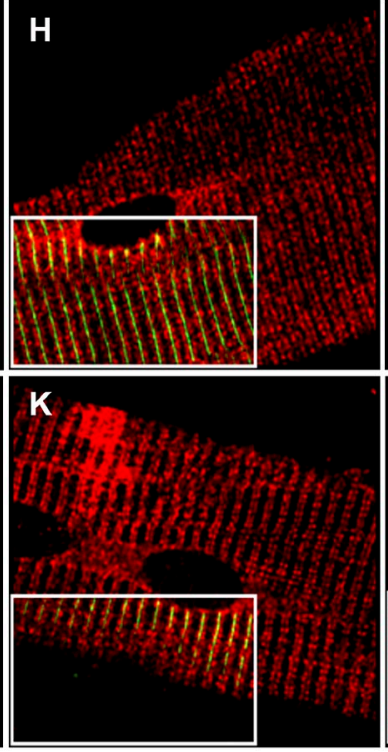

RyR-1/a-actinin

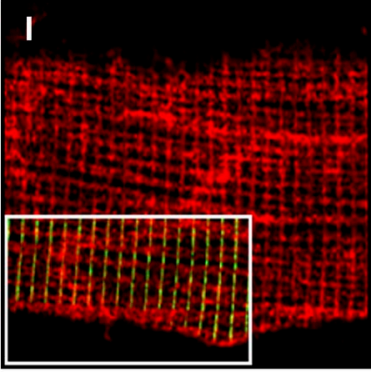

$\mathbf{L}$

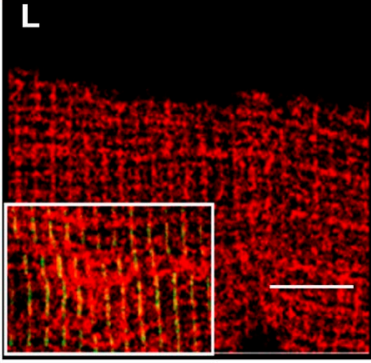

caveolin-3/ $\alpha$-actinin
Obscurin $\mathrm{KO}$ mice show reduced exercise tolerance, loss of muscle strength, and sarcolemmal fragility

Previous work demonstrated that EDL muscle contractile performance studied in vitro is not altered in obscurin $\mathrm{KO}$ mice (Lange et al., 2009). However, given the importance of dystrophin localization at costameres for maintenance of sarcolemma integrity, we decided to evaluate whether the altered localization of dystrophin could affect the membrane stability of obscurin KO skeletal muscle fibers. To this end, 5-mo-old control and obscurin $\mathrm{KO}$ mice were trained to run uphill on a treadmill as detailed in Materials and methods. Surprisingly, the running performance of obscurin KO mice was lower than that of agematched controls, as the distance covered at exhaustion by obscurin $\mathrm{KO}$ mice was lower in the first session and decreased progressively in subsequent sessions (Fig. 7 A). We reasoned that the different performance of obscurin KO mice expressed in the nonvoluntary running exercise could be explained as loss of muscle strength compared with control mice. On this basis, we performed a forelimbs grip test to evaluate muscle strength at the end of the last session. Indeed, our measurements revealed a $40 \%$ reduction in forelimb muscles of obscurin $\mathrm{KO}$ mice $(49.7 \pm 6.7 \mathrm{mN} / \mathrm{g}$ in control mice and $28.6 \pm 10.5 \mathrm{mN} / \mathrm{g}$ in obscurin KO mice; $\mathrm{P}<0.001$ ). We extended the comparison to the performance in downhill running on a treadmill, an exercise that is less energetically demanding but has a greater component of eccentric contractions compared with uphill running. The results confirmed that the distance covered at exhaustion in three subsequent sessions was dramatically decreased in obscurin KO mice (Fig. 7 B). Finally, to evaluate whether sarcolemma damage could be involved in such a decline of muscle performance, Evans blue dye (EBD) was intraperitoneally injected 
Figure 6. Association of dystrophin with the DGC in obscurin KO muscles is reduced. Analysis of tibialis anterior muscle lysates from control (CNTR) and obscurin $\mathrm{KO}$ animals using sucrose gradient fractionation indicated changes to dystrophin distribution in obscurin $\mathrm{KO}$ muscles. (A-H) In control muscles (A and B), dystrophin is enriched in fractions 3-5 with other DGC core components like $\beta$-dystroglycan ( $C$ and $D), \alpha$-sarcoglycan ( $E$ and $F)$, and $\gamma$-sarcoglycan ( $G$ and $H)$. Obscurin KO muscles, however, display a wider dystrophin distribution pattern (extending into fractions 7-13; A [bottom] and $\mathrm{B}$ ), indicating a weaker association of dystrophin with the DGC. (I-N) Other DGC components as well as caveolin-1 (I and J), caveolin-3 (K and L), and $\beta 1 D$-integrin ( $M$ and $N$ ) are unchanged in obscurin $\mathrm{KO}$ muscle compared with controls. Graphs represent the distribution of the DGC core components present in each fraction and are reported as the percentage of the total protein. Values refer to the blots shown in the figure.
A

\section{dystrophin}

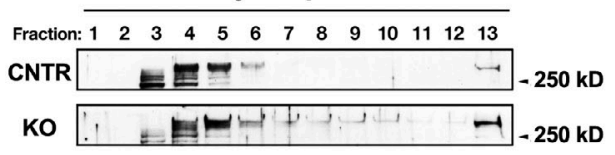

C

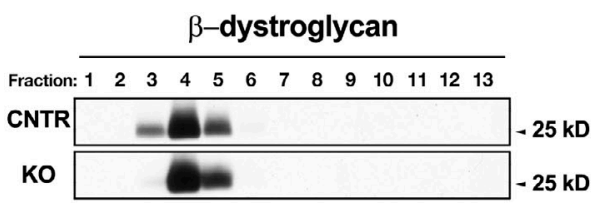

E

$\alpha$-sarcoglycan

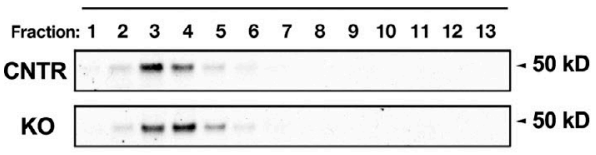

$\mathbf{G}$

$\gamma$-sarcoglycan

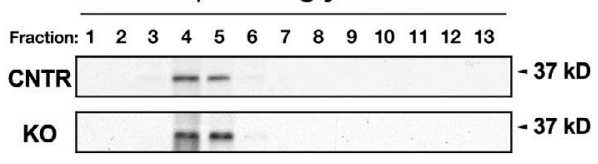

I

caveolin-1

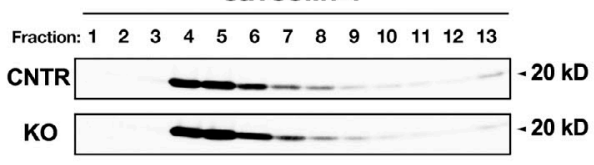

$\mathbf{K}$

caveolin-3

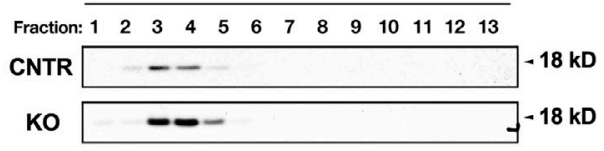

M

\section{B1D-integrin}

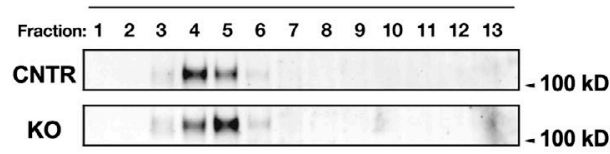

B

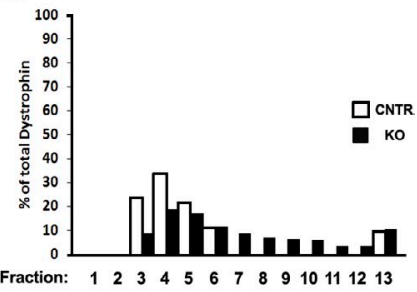

D

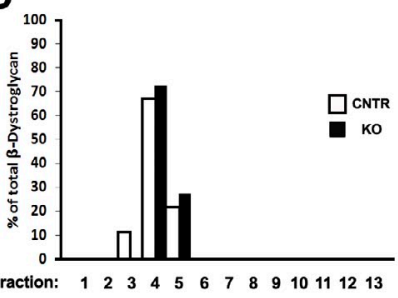

$\mathbf{F}$

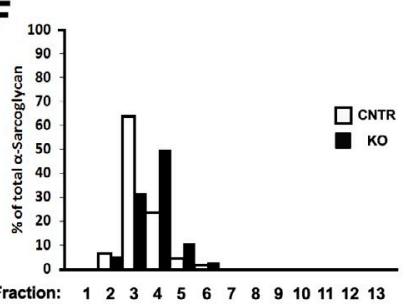

H.

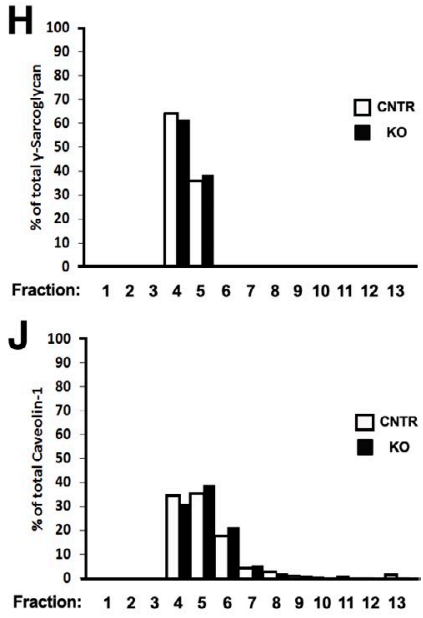

$\mathbf{L} 100$
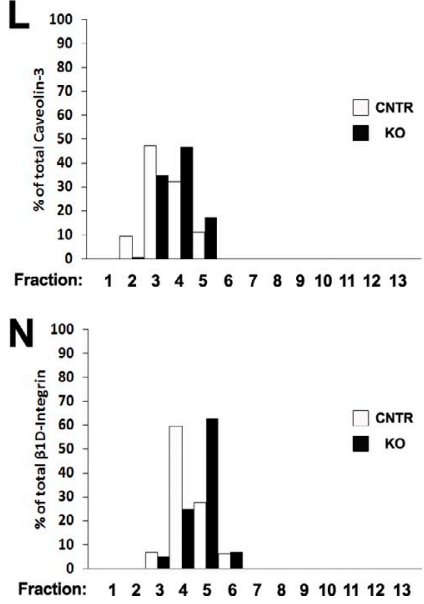

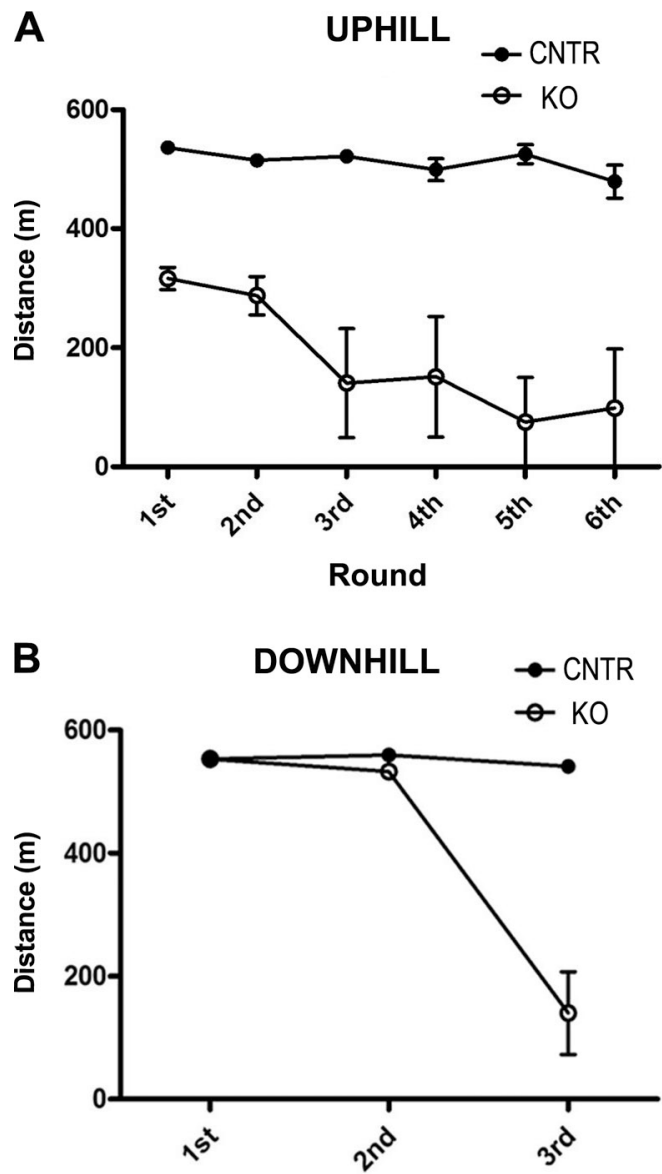

Round

Figure 7. Behavioral assessment of muscle function. (A) Impaired exercise tolerance in treadmill uphill running: 5 -mo-old $(n=8)$ control and obscurin $\mathrm{KO}$ mice were treadmill exercised twice a day for $3 \mathrm{~d}$ (see Materials and methods for details). The distance traveled by obscurin $\mathrm{KO}$ mice is lower and shows a progressive decline in subsequent sessions compared with age-matched control animals. (B) The decline of exercise tolerance measured as distance traveled in subsequent sessions is even more pronounced in downhill running: 5-mo-old control $(n=8)$ and obscurin KO mice $(n=8)$ were treadmill exercised twice a day, but exercise was interrupted at the third session to avoid useless stress to animals. Results are presented as means and SDs. Bars representing SD for mean values corresponding to rounds $1-3$ of control and rounds 1 and 2 of obscurin $\mathrm{KO}$ mice are not visible because of graph scale. CNTR, control.

just before the last running session, and membrane integrity was subsequently evaluated by microscope visualization of EBD uptake in muscle fibers. Analysis of tibialis anterior (Fig. 8, A and C) and diaphragm (Fig. 8, B and D) muscles showed a higher number of EBD-positive fibers in obscurin $\mathrm{KO}$ muscles (25 $\pm 0.7 \%$ and $35 \pm 1.8 \%$ ) compared with controls $(1 \pm 0.1 \%$ and $5 \pm 0.4 \%) ; \mathrm{P}<0.05$. Noteworthy, the sarcolemma damage observed after exercise in obscurin $\mathrm{KO}$ mice, at least as measured by EBD uptake, is comparable to what was observed in sedentary mdx mice by us and other laboratories (Petrof et al., 1993; Mathur et al., 2011; Serra et al., 2012). Altogether, these data indicate that the lack of obscurin determines a pronounced muscle weakness likely explained by sarcolemma fragility when obscurin $\mathrm{KO}$ muscle fibers are forced to undergo a prolonged mechanical stress.

\section{EBD uptake}

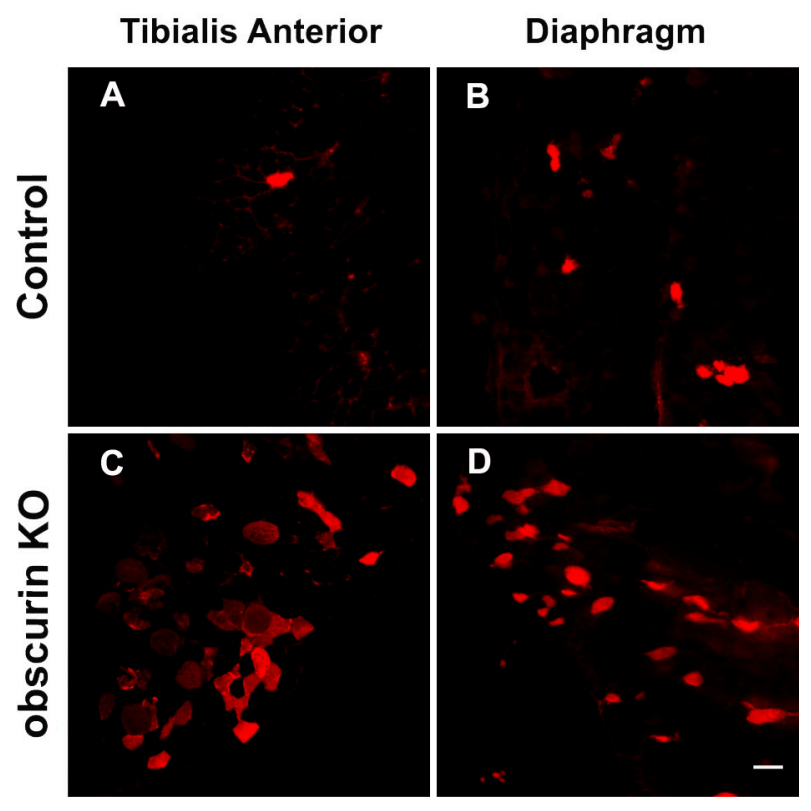

Figure 8. Lack of obscurin results in sarcolemma fragility after exercise. $(A-D)$ Evans blue dye (EBD) was injected intraperitoneally $12 \mathrm{~h}$ before the last running session. Analysis of $E B D$ uptake in tibialis anterior ( $A$ and $C$ ) and diaphragm ( $B$ and $D)$ reveals that the obscurin $K O$ condition results in sarcolemma fragility. A higher number of EBD-positive fibers was found in exercised obscurin $\mathrm{KO}$ muscles when compared with controls. Bar, $50 \mu \mathrm{m}$.

\section{Discussion}

Dystrophin and members of the DGC are key elements in the organization of costameres at $\mathrm{Z}$ disks, where they connect the extracellular matrix, the sarcolemma, and the subsarcolemmal cytoskeleton to avoid sarcolemmal damage caused by physical stress associated with muscle contraction (Ervasti and Campbell, 1991; Ervasti, 2003). Recent results have shown that the assembly of dystrophin and $\beta$-dystroglycan at costameres requires expression of the muscle-specific ankyrin isoforms ankB and ankG (Ayalon et al., 2008). Independent lines of research, over the last years, have also shown that muscle-specific ankyrins, including sAnk1.5 but also ankB and ankG, contain characteristic binding sites for the myofibrillar protein obscurin (Bagnato et al., 2003; Hopitzan et al., 2005; Cunha and Mohler, 2008). Accordingly, we investigated whether obscurin might participate in the subsarcolemma localization of ankB and ankG and, hence, of dystrophin and $\beta$-dystroglycan at costameres. Immunostaining experiments indicated that obscurin, ankB, and ankG were localized at the subsarcolemmal level. In particular, ankB and obscurin were predominantly found at the $\mathrm{M}$ band and to a much lesser extent at the $\mathrm{Z}$ disk, whereas the ankG signal was mainly observed at the $\mathrm{Z}$ disk. In skeletal muscle fibers from obscurin $\mathrm{KO}$ mice, ankB was no longer localized at the $\mathrm{M}$ band but presented a disorganized distribution with a partial alignment observed in correspondence with the $\mathrm{Z}$ disk. The ankG localization pattern was not altered in obscurin KO fibers. These results are consistent with a role of obscurin in the localization of ankB at the $\mathrm{M}$ band. The localization of ankG at 
the $\mathrm{Z}$ disk could be mediated by interactions of ankG with the intermediate filament-associated proteins plectin- 1 and filamin C (Maiweilidan et al., 2011). We found that ankB and obscurin can be coimmunoprecipitated from skeletal muscle protein lysates and that both OBDs are required for localization of ankB to the $\mathrm{M}$ band. Previous work indicated that $\beta 2$-spectrin participates in the localization of ankB to the $\mathrm{M}$ band in cardiomyocytes (Mohler et al., 2004), whereas in skeletal muscle fibers, $\beta 2$-spectrin appears to contribute to ankB localization at $\mathrm{Z}$ disks (Ayalon et al., 2011). We found that the GFP-ankB fusion protein was predominantly localized at the M-band region in control mice but was redistributed near the $\mathrm{Z}$ disk in obscurin $\mathrm{KO}$ mice. Therefore, it is conceivable that in the absence of obscurin, which would represent the major M-band localization determinant for ankB, $\beta 2$-spectrin could represent the only site of localization for ankB at the $\mathrm{Z}$ disk in skeletal muscle. Altogether, these results suggest the existence of two separate systems cooperating in the localization of ankB in skeletal muscle fibers, with obscurin being responsible for localization at the $\mathrm{M}$ band, whereas $\beta 2$-spectrin may link ankB at the $\mathrm{Z}$ disk. However, based on available data, it cannot be excluded that the small amount of obscurin present at the $\mathrm{Z}$ disk may also contribute to localization of ankB at this site.

Knockdown of ankB or $\beta 2$-spectrin has been reported to result in the complete absence of dystrophin and $\beta$-dystroglycan at costameres in skeletal muscle fibers (Ayalon et al., 2011). This differs from our findings in obscurin $\mathrm{KO}$ mice, in which only the localization of dystrophin at costameres was reduced, but not abolished, whereas costameric localization of $\beta$-dystroglycan and sarcoglycans was not altered. The residual localization of dystrophin at costameres observed in obscurin KO mice could be explained by the residual amounts of ankB observed in obscurin $\mathrm{KO}$ muscle fibers. The presence of ankG at costameres in obscurin $\mathrm{KO}$ mice may further explain the preserved localization of $\beta$-dystroglycan and sarcoglycans. It should be noted that, both in this study with obscurin $\mathrm{KO}$ mice and in previous studies with ankB and $\beta 2$-spectrin knockdown mice (Ayalon et al., $2008,2011)$, the dystrophin signal was either reduced or absent when analyzed by immunostaining, whereas when measured by Western blotting, the dystrophin protein levels were similar to those of control mice. We think that this apparent discrepancy could be resolved considering that dystrophin, if not retained to costameres by ankB, may diffuse either across the sarcolemma and/or remain in internal cellular compartments, thus becoming virtually undetectable by confocal microscopy. Indeed, reduced localization of dystrophin at costameres was also supported by sucrose gradient fractionation experiments that indicated a reduced association of dystrophin with other core members of the DGC in obscurin KO muscles.

In addition, the organization of subsarcolemma microtubules in obscurin $\mathrm{KO}$ muscle fibers was severely altered, similarly to what observed after knockdown of $\beta 2$-spectrin or of ankB and in muscle fibers of $\mathrm{mdx}$ mice (Prins et al., 2009; Ayalon et al., 2011). In a recent study, depletion of obscurin in developing zebrafish embryos has been shown to alter the organization of skeletal muscle, including the pattern of dystrophin and $\alpha$-dystroglycan (Raeker and Russell, 2011). In the obscurin
KO mouse, the reduced localization of dystrophin at costameres is observed in the presence of a preserved organization of other DGC components. Nevertheless, the reduced running endurance capacity and the severe sarcolemmal damage observed in muscle fibers of obscurin KO mice after exercise clearly indicate that the contribution of obscurin to the correct localization of dystrophin at costameres, likely mediated by its interaction with ankB, is required to prevent sarcolemma fragility, even if other components of the DGC are unaffected. However, the reduced exercise tolerance of obscurin $\mathrm{KO}$ mice that can be observed already in the first round of uphill running suggests that additional mechanisms, including the altered organization of the SR in obscurin KO mice (Lange et al., 2009; Ackermann et al., 2011), may contribute to the decreased performance of these mice.

How obscurin deletion and the resulting ankB mislocalization affect the costameric localization of dystrophin at the level of the $\mathrm{Z}$ disk is not obvious, given that the main localization of obscurin and ankB is at the level of the $\mathrm{M}$ band. It has been demonstrated that ankB can interact directly with dystrophin and, through dynactin-4, with microtubules (Ayalon et al., 2008). In addition, dystrophin can also directly bind to microtubules (Prins et al., 2009). It is therefore possible to hypothesize that ankB at the $\mathrm{M}$ band may contribute to the assembly of subsarcolemmal microtubules that normally extend along the sarcomere to the region of the $\mathrm{Z}$ disk where they connect to dystrophin and other costameric proteins (see the proposed model in Fig. 9). It cannot be excluded that the minor amount of ankB localized at the $\mathrm{Z}$ disk can also directly interact with dystrophin. Actually, it is interesting to point out that the effects of $\beta 2$-spectrin knockdown on ankB and dystrophin localization (Ayalon et al., 2011) are closely related to those observed here in obscurin KO muscle fibers. It can then be inferred that obscurin and $\beta 2$-spectrin are both required for the correct localization of ankB, the organization of the subsarcolemmal cytoskeleton, and for dystrophin localization at costameres. As a consequence, absence of either one of these proteins would result in a significant alteration of this system. Obscurinmediated localization of ankB at the $\mathrm{M}$ band recalls early evidence of costamere-like assemblies in register with the $\mathrm{M}$ bands that have long been hypothesized (Nelson and Lazarides, 1983; Porter et al., 1992; Ervasti, 2003). The newly discovered role of the obscurin and ankB interaction at subsarcolemma appears to be supportive of this hypothesis. It is worth noting that the muscle phenotype of obscurin $\mathrm{KO}$ mice that lack dystrophin but contain a conserved presence of the dystroglycan complex is clearly different than mdx mice, in which both the dystrophin and dystroglycan complex are absent. Compared with $\mathrm{mdx}$ mice, muscles from obscurin KO mice do not undergo a continuous process of degeneration-regeneration, which in mdx older than 4 wk presents many centronucleated fibers, degenerated fibers, fibrosis, and parvicellular infiltration. Such structural alterations accompany the decline of isometric tension developed by diaphragm and limb skeletal muscles (Lynch et al., 2001a,b; Faulkner, 2003). In obscurin KO mice, a significant presence of centronucleated fibers was only detected around $1 \mathrm{yr}$ of age (Lange et al., 2009). However, in both mdx and obscurin KO 


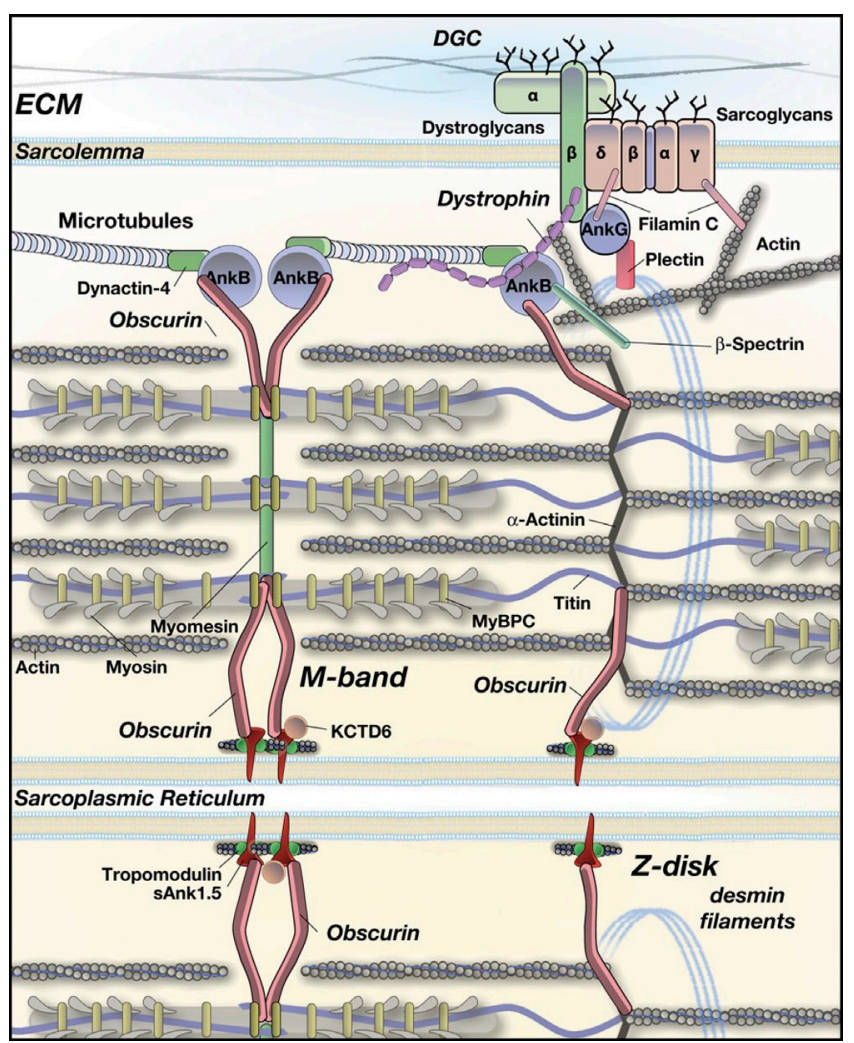

Figure 9. Proposed model for the obscurin, ankB, and microtubule network interactions mediating dystrophin localization at the subsarcolemma in skeletal muscles. In this model, only known or proposed interactions in skeletal muscle are reported. For other interactions occurring in other cell types, please see reviews by Bennett and Baines (2001), Bennett and Healy (2009), and Cunha and Mohler (2011). In skeletal muscle fibers, ankB is predominantly localized at the $M$ band and, to a lesser extent, at the $Z$ disk. AnkB localization at the $M$ band relies on the interaction with obscurin on the sarcomere, whereas localization at the $Z$ disk depends on the interaction with $\beta 2$-spectrin associated to the actin microfilaments (Ayalon et al., 2011) and probably with the smaller amount of obscurin at the $Z$ disk. At the $M$ band, a microtubule lattice is organized by dynactin- 4 , ankB, and obscurin. In parallel, at the $Z$ disk, a complex made by microtubules, dynactin- 4 , ankB, $\beta 2$-spectrin, and dystrophin is formed, in which ankB can directly interact with $\beta 2$-spectrin, dynactin- 4 , and dystrophin. In the absence of obscurin, this M-band complex is disrupted, causing the subsarcolemmal microtubule lattice to collapse, thus affecting and reducing the dystrophin localization at Z disks. Nevertheless, the small amount of ankB observed in obscurin $\mathrm{KO}$ muscle fibers, through the interaction with $\beta 2$-spectrin at the $Z$ disks, can still support a residual organization of dystrophin at costameres, in addition to direct interactions between dystrophin and the actin microfilaments network and/or other components of the DGC (Clark et al., 2002; Ervasti, 2003). Localization of ankG at costameres may occur via its interactions with $\beta$-dystroglycan, plectin, and filamin $C$ in an obscurin-independent manner (Maiweilidan et al., 2011).

muscle, the sensitivity to stress and, in particular, to eccentric exercise is very pronounced, definitely much more pronounced than in control animals. From this evidence, it would appear as if the presence of the dystroglycan complex is a guarantee that avoids damage in the condition of ordinary activity but is not sufficient when high and repetitive mechanical stresses are applied. Certainly, additional work will be required to better define these specific aspects.

In conclusion, the results presented in this work appear to further advance our understanding of the physiological roles of obscurin in the organization of striated muscle cells. The ability to establish multiple interactions with sarcomeric proteins, including titin, myomesin, and myosin-binding protein $\mathrm{C}$, suggests a role of obscurin in the organization of the $\mathrm{M}$ band in sarcomeres (Kontrogianni-Konstantopoulos et al., 2009; Gautel, 2011; Pfuhl and Gautel, 2012). Additional evidence has also shown that obscurin, by interacting with the musclespecific ankyrin isoform sAnk1.5, is important for the correct alignment of the SR along myofibrils (Bagnato et al., 2003; Kontrogianni-Konstantopoulos et al., 2003; Lange et al., 2009) and for sAnk1.5 protein stability (Lange et al., 2012). The data reported here add a new twist to obscurin functions caused by interaction with proteins of the extrasarcomeric cytoskeleton. In fact, our data indicate that obscurin localized at the subsarcolemma contributes to the organization of the membraneassociated microtubule cytoskeleton and to dystrophin localization at costameres, through its interaction with ankB. Accordingly, obscurin appears to represent a multifunctional anchoring protein that, on one hand, establishes interactions with sarcomeric proteins and, on the other hand, enables complex formation with extrasarcomeric proteins, such as the muscle-specific ankyrin isoforms, that help to connect the sarcomeres with the SR and with the subsarcolemmal cytoskeleton.

\section{Materials and methods}

\section{Mice}

The development of obscurin global KO mice was described previously (Lange et al., 2009). In brief, the obscurin-coding exon 1 was replaced with a lacZ/GFP-H2B/Neomycin (Neo) cassette, whereby lacZ and Neo genes are flanked by LoxP and FLP recognition target sites, respectively. Mice used in this study were genotyped by duplex PCR on genomic DNA purified from tail tissue with the genotyping kit (Gentra Puregene; QIAGEN), according to manufacturer's instructions, using the following primers: obscurin forward, 5'-TAAGATTCTTTTCTGCAAGCAGTC-3'; obscurin reverse, 5'-AGTGTGTTTTGAGGAAGGAGAGAG-3'; and Neo FLP recognition target forward, 5'-AATGGGCTGACCGCTTCCTCGT-3'.

\section{Immunostaining and confocal microscopy}

Fibers obtained from FDB of 6-8-mo-old mice were fixed in 1\% PFA-0.5\% Triton X-100 for $1 \mathrm{~h}$ at room temperature. The bundles of fibers were further permeabilized with $0.5 \%$ Triton $\mathrm{X}-100$ in Hepes for 3 min and blocked with $10 \%$ goat serum in BSA (fraction V; Sigma-Aldrich) for 1 h. 8-pm cross sections were obtained from tibialis anterior and diaphragm using a cryostat (CM 1850; Leica) and mounted on Superfrost Plus slides (Thermo Fisher Scientific). Before immunostaining, sections were blocked in 5\% goat serum in $0.2 \%$ BSA for $1 \mathrm{~h}$. In all immunostaining experiments, primary antibodies were prepared in 1 or $0.2 \% \mathrm{BSA}$ and incubated overnight at $4^{\circ} \mathrm{C}$. After three washes of 10 min each, samples were incubated for $1 \mathrm{~h}$ at room temperature with the secondary antibodies. After final washing (three times at $10 \mathrm{~min}$ each), samples were mounted on glass slides and covered with coverslips. Samples were imaged using a confocal microscope (LSM510 META; Carl Zeiss) with a Plan-Apochromat 63x oil immersion, 1.4 NA objective. Fluorescent secondary antibodies Cy2-conjugated antimouse and Cy3-conjugated anti-rabbit were obtained from Jackson ImmunoResearch Laboratories, Inc. Images were acquired at $23^{\circ} \mathrm{C}$ using the antifade reagent (ProLong Gold; Invitrogen) as imaging medium with the LSM acquisition software (Carl Zeiss). Image analysis was performed using the ImageJ software. Several regions were drawn in muscle fibers after dystrophin staining, and the dystrophin signal was calculated as the mean intensity within the region, after subtraction of the mean background intensity of a nearby area. In all cases, acquisition conditions within an experiment were identical. Arbitrary units are reported as means \pm SD and analyzed by a two-tailed Student's $t$ test.

\section{Construct preparation and in vivo electroporation}

GFP constructs were prepared from the pEGFP-N1 plasmid bearing the human ankB sequence containing only the OBD2 site. The full-length ankB 
sequence was obtained by inserting a fragment containing both the OBD $1 / 2$ sites cloned from a human cDNA. The full-length ankB was then transferred into the pEGFP-C2 vector (Takara Bio Inc.). All GFP-tagged constructs used in this study were prepared using pEGFP-C2-ankB as a template. GFPankB- $\triangle O B D 1,-\triangle O B D 2$, and $-\triangle O B D 1 / 2$ deletion mutants were obtained by removing one or both $\mathrm{OBD}$ sites by PCR. GFP-tagged $\triangle \mathrm{SBD}$ constructs were obtained by removing the ZU5 domain (ZO-1 and Unc-5-like netrin receptor 5) +55 aa corresponding to the minimal spectrin-binding region (966-1,125 aa) of ankB as described in Mohler et al. (2004). The SBD $(943-1,192 \mathrm{aa})$ and $\mathrm{OBD} 1+2(1,756-1,871 \mathrm{aa})$ sequences used for the GFP-SBD and GFP-OBD1+2 constructs, respectively, were cloned from ankB by PCR. All the constructs used in the study were verified by DNA sequencing. In vivo electroporation experiments were performed on FDB muscles injected with $2 \mathrm{mg} / \mathrm{ml}$ bovine hyaluronidase (Sigma-Aldrich) $45 \mathrm{~min}$ before electroporation (Legrand et al., 2008). Control and obscurin $\mathrm{KO}$ mice were anesthetized with $1.25 \%$ Avertin (Roche) solution, and $10 \mu \mathrm{g}$ plasmid constructs in $20 \mu \mathrm{l}$ PBS was injected into the muscle using a microsyringe (Exmire; Ito Corporation). Immediately after injection, muscles were placed between paddle electrodes, and a 20-ms pulse train (120 V, 20-ms length, and 1-s intervals) was delivered using the pulse generator (Electro Square Porator ECM 830; BTX-Genetronics, Inc.). Mice were sacrificed $8 \mathrm{~d}$ after electroporation.

\section{Antibodies}

Polyclonal rabbit antibodies raised against different epitopes of obscurin were a gift of M. Gautel (King's College London, London, England, UK). The antibody against obscurin was obtained by immunizing rabbits with the A7VI GST fusion protein and has been previously described (Bagnato et al., 2003; Giacomello and Sorrentino, 2009). A polyclonal antibody against ankB was provided by V. Bennett (Duke University, Durham, NC), a polyclonal antibody specific for ankG was provided by K. Kordeli (Centre National de la Recherche Scientifique-Université Jussieu, Paris, France), polyclonal antibody against $\alpha$-sarcoglycan was obtained from R. Betto (University of Padua, Padua, Italy), and a polyclonal antibody against $\beta 1 D$-integrin was provided by G. Tarone (University of Turin, Turin, Italy). The polyclonal antidystrophin (RB-9024) was purchased from Thermo Fisher Scientific, the monoclonal antidystrophin (clone MANDRA1), the polyclonal antibodies against $\beta-, \gamma_{-}$, and $\delta$-sarcoglycans, the monoclonal anti- $\alpha$-tubulin (clone B-5-1-2), and the monoclonal antibody anti- $\alpha$-actinin (clone $5 \mathrm{C} 5$ ) were all purchased from Sigma-Aldrich, the monoclonal anti- $\beta$-dystroglycan (product code: NCL-b-DG) was purchased from Novocastra, the polyclonal antibody anti- $\gamma$-actin and the $A B 993$ polyclonal antibody anti- $\beta 2$-spectrin were purchased from EMD Millipore, the monoclonal anti-dihydropyridine receptor was purchased from Thermo Fisher Scientific, the monoclonal anti-caveolin-3 was purchased from BD, a rabbit polyclonal anti-RyR 1 (ryanodine receptor type 1) was obtained by injecting a GST fusion protein encoding the divergent region 3 of RyR 1 as previously described (Giannini et al., 1995), and conjugated WGA Alexa Fluor 488 was obtained from Molecular Probes. Antibodies used in sucrose gradient experiments are as follows: Caveolin-1 was obtained from Cell Signaling Technology. Caveolin-3 was obtained from BD. The polyclonal dystrophin antibody $(\mathrm{H}-300)$ was purchased from Santa Cruz Biotechnology, Inc. Vector Laboratories provided monoclonal antibodies to $\alpha$ - and $\gamma$-sarcoglycans (VP-A105 and VP-G803, respectively). The monoclonal antibody to $\beta$-dystroglycan, MANDAG2, developed by G.E. Morris (Institute of Science and Technology in Medicine, Keele University, Staffordshire, England, UK), was obtained from the Developmental Studies Hybridoma Bank. Polyclonal $\beta$ 1D-integrin was produced in the laboratory of B. Ross (University of California, San Diego School of Medicine, La Jolla, CA).

\section{Treadmill exercise, forelimbs grip strength test, and EBD uptake experiments}

Control and obscurin KO 5-mo-old mice $(n=8)$ were treadmill exercised with a rolling belt instrument (LE $8710 \mathrm{M}$; Panlab) twice a day for $3 \mathrm{~d}$ $\left(30 \mathrm{~min}, 10^{\circ}\right.$ uphill angle, and $30 \mathrm{~cm} / \mathrm{s}$ ) for the uphill running according to the protocol proposed by Ayalon et al. (2011), whereas three rounds (45 min, $15^{\circ}$ downhill angle, and $20 \mathrm{~cm} / \mathrm{s}$ ) were performed for downhill exercise. The day before final exercises of uphill and downhill, EBD was injected intraperitoneally (1 mg/0.1 ml per $10 \mathrm{~g}$ of body weight). After the last running session of uphill running, a forelimbs grip test was performed to measure the maximum strength of forelimbs of all control and obscurin $\mathrm{KO}$ mice. In brief, the mice were held by the tail and lowered on a grid connected to a force sensor, allowing only the front paws to grip the grid. The mice were then pulled back horizontally until they released the grid, and six serial strength measurements were recorded. The six strength data were averaged and normalized to body weight and expressed in normals per gram. Tibialis anterior and diaphragm muscles were removed from exercised mice and snap frozen using optimum cutting temperature (Tissue-Tek; Sakura) in cooled isopentane chilled to $-165^{\circ} \mathrm{C}$ in liquid nitrogen. Muscles were cross sectioned $(20 \mu \mathrm{m})$ throughout the length of the muscles to evaluate the extent of EBD uptake. Positive fibers were imaged with a $20 \times$ objective.

\section{Sucrose gradients, SDS-PAGE, and immunoblotting}

Analysis of DGC protein components on sucrose gradients of tibialis anterior muscles obtained from control and obscurin $\mathrm{KO}$ mice was performed as previously described (Crosbie et al., 1997). Muscles were homogenized in ice-cold immunoprecipitation lysis buffer (Thermo Fisher Scientific) supplemented with protease and phosphatase inhibitors (Roche). Soluble proteins were separated from insoluble proteins via centrifugation at $14,000 \mathrm{~g}$ for $10 \mathrm{~min}$ at $4^{\circ} \mathrm{C}$. $600 \mathrm{\mu g}$ of soluble proteins was loaded onto a $5-20 \%$ linear sucrose gradient (Gradient immunoprecipitation station; Biocomp Instruments) and placed in an ultracentrifuge (Optima L-90K; Beckman Coulter) at $350,000 \mathrm{~g}$ overnight at $4{ }^{\circ} \mathrm{C}$. The next day, the gradients were fractionated into 13 fractions, and 20-40 $\mu$ of each fraction was resolved on 4-20\% SDS-PAGE gradient gels and subsequently transferred onto nitrocellulose overnight for immunoblot analysis. For total protein immunoblotting experiments, tissues were homogenized in lysis buffer containing $4 \mathrm{M}$ urea, $3.8 \%$ SDS, $20 \%$ glycerol, and $75 \mathrm{mM}$ Tris- $\mathrm{HCL}$, $\mathrm{pH} 6.8$, using a homogenizer (ULTRA TURRAX T 10; IKA) three times for $10 \mathrm{~s}$. Lysates were incubated for $1 \mathrm{~h}$ on ice and then centrifuged at 10,000 $\mathrm{g}$ for $5 \mathrm{~min}$ at $4^{\circ} \mathrm{C}$ in a microcentrifuge (Eppendorf), and the supernatant was conserved at $-80^{\circ} \mathrm{C}$ until use. Total muscle proteins were separated by SDS-PAGE using a $5 \%$ gel overnight at $4{ }^{\circ} \mathrm{C}(30 \mathrm{~V})$ and then transferred onto polyvinylidene fluoride (PVDF) membrane overnight at $4^{\circ} \mathrm{C}(80 \mathrm{~mA})$. Membranes were blocked with $5 \%$ milk in TBS-T $(20 \mathrm{mM}$ Tris- $\mathrm{HCl}, \mathrm{pH} 7.4$, $150 \mathrm{mM} \mathrm{NaCl}$, and $0.05 \%$ Tween 20) for $1 \mathrm{~h}$ at room temperature. Membranes were incubated with primary antibodies diluted in $5 \%$ milk in TBS-T for $1 \mathrm{~h}$ at room temperature. After three washes with TBS-T of $10 \mathrm{~min}$ each, membranes were incubated for $1 \mathrm{~h}$ at room temperature with HRP-conjugated secondary antibodies. After further washing with TBS-T (three times for $10 \mathrm{~min}$ each), chemiluminescence was detected using the Western blotting reagents (ECL Prime; GE Healthcare). HRP-conjugated secondary antibodies were obtained from Jackson ImmunoResearch Laboratories, Inc.

Images from different experiments were captured on film and quantified in arbitrary units using ImageJ software. Values are reported as means \pm SD and analyzed by two-tailed Student's $t$ test.

\section{Coimmunoprecipitation}

Solubilized proteins from mouse skeletal muscle were prepared as previously described (Mohler et al., 2005). In brief, skeletal muscles were dissected, flash frozen in liquid nitrogen, and ground into a fine powder, which was resuspended in $50 \mathrm{mM}$ Tris $\mathrm{HCl}, \mathrm{pH} 7.4,10 \mathrm{mM} \mathrm{NaCl}, 0.32$ $M$ sucrose, $5 \mathrm{mM}$ Na EDTA, $2.5 \mathrm{mM}$ Na EGTA, $1 \mathrm{mM}$ EDTA, pH 8.0, and protease inhibitors. The homogenate was centrifuged at $1,000 \mathrm{~g}$ to remove nuclei, and Triton X-100 and deoxycholate were added to the final concentrations of $1.5 \%$ Triton $\mathrm{X}-100$ and $0.75 \%$ deoxycholate, respectively. The lysate was pelleted at $100,000 \mathrm{~g}$ for $1 \mathrm{~h}$ at $4{ }^{\circ} \mathrm{C}$, and the supernatant was recleared at $100,000 \mathrm{~g}$ for $1 \mathrm{~h}$ to remove residual large membranes or vesicles. The resulting supernatant was used for immunoprecipitation. Solubilized proteins were diluted at the concentration of $1 \mu \mathrm{g} / \mu \mathrm{l}$ in $10 \mathrm{mM}$ Tris, $\mathrm{pH} 7.4,150 \mathrm{mM} \mathrm{NaCl}, 5 \mathrm{mM}$ EDTA, $1 \%$ Triton X-100, $1 \mathrm{mMPMSF}$, and $1 \mathrm{mM} \mathrm{Na}_{3} \mathrm{VO}_{4}$ and precleaned with protein A-Sepharose beads (GE Healthcare) for $1 \mathrm{~h}$ at $4^{\circ} \mathrm{C}$. $500 \mathrm{\mu g}$ of precleared solubilized proteins were incubated overnight at $4{ }^{\circ} \mathrm{C}$ with the antibody against obscurin (Giacomello and Sorrentino, 2009) and with an unrelated antibody as a negative control. Afterward, the complexes were incubated with $60 \mu \mathrm{l}$ protein A-Sepharose beads (50\% slurry) for $4 \mathrm{~h}$. Beads were washed four times with dilution buffer to remove nonspecifically bound proteins. The immune complexes were treated with sample buffer and analyzed on 4-15\% stain-free precast gels (Criterion-TGX; Bio-Rad Laboratories) transferred on PVDF (EMD Millipore) membranes for immunoblot analysis.

\section{GST pull-down assay}

$100 \mathrm{mg}$ proteins from mouse skeletal muscle was solubilized in $1 \mathrm{ml}$ TBS containing $1 \%$ Triton X-100 and protease inhibitors as previously described by Michele et al. (2002) and resuspended at the concentration of $1 \mathrm{\mu g} / \mathrm{\mu l}$. Pull-down assays were performed with $500 \mu \mathrm{g}$ protein lysates from skeletal muscle and $15 \mu \mathrm{g}$ of the A7VI-GST fusion protein $(50 \mu \mathrm{l}$ of beads with $50 \%$ slurry) containing the C-terminal region of obscurin (aa 6,215-6,353) 
encompassing the ankyrin binding sites (Armani et al., 2006) and GST as negative control in pull-down buffer $(20 \mathrm{mM}$ Tris, pH 8, $200 \mathrm{mM} \mathrm{NaCl}$, 1\% Triton X-100, 1 mM PMSF, 1 mM Na$V_{3} V_{4}, 1$ mM EDTA, pH 8.0, and protease inhibitors). After $2 \mathrm{~h}$ at $4^{\circ} \mathrm{C}$, the complexes were washed four times with pull-down buffer (Salanova et al., 2002; Armani et al., 2006). Bound proteins were eluted and separated by SDS-PAGE using 4-15\% stain-free precast gels (Criterion-TGX) transferred onto PVDF membranes overnight for immunoblot analysis.

\section{Statistics}

Statistical analysis was performed using the Student's $t$ test. Results are presented as means $\pm S D$, and $p$-values are shown.

\section{Online supplemental material}

Fig. S1 shows the localization of GFP-ankB- $\triangle O B D 2$ and GFP-ankB$\triangle \mathrm{OBD} 1 / 2$ in vivo FDB muscles of control and obscurin KO mice. Fig. S2 shows localization of $\beta 2$-spectrin in control, obscurin $\mathrm{KO}$, and $\mathrm{mdx}$ muscle fibers. Fig. S3 shows localization of GFP-SBD and GFP-OBD1+2 in FDB muscle fibers of control mice. Fig. S4 shows immunofluorescence analysis for $\alpha-, \beta-, \gamma-$, and $\delta$-sarcoglycans, $\beta 1 D$-integrin, and $\gamma$-actin in control and obscurin $\mathrm{KO}$ muscle fibers. Fig. S5 shows immunostaining of tibialis anterior cross sections with WGA and dystrophin (MANDRA1) antibodies and Western blot analysis of protein lysates from tibialis anterior, EDL, and soleus of control and obscurin $\mathrm{KO}$ mice. Online supplemental material is available at http://www.jcb.org/cgi/content/full/jcb.201205118/DC1. Additional data are available in the JCB DataViewer at http://dx.doi .org/10.1083/jcb.201205118.dv.

We thank Drs. V. Bennett, M. Gautel, K. Kordeli, R. Betto, B. Ross, and G. Tarone for providing antibodies and plasmids. We also thank Dr. A. De Matteis for kindly providing the antibody to $\beta 2$-spectrin.

J. Chen is funded by grants from the National Institute of Arthritis and Musculoskeletal and Skin (RO IARO59334) and the National Heart, Lung, and Blood Institute. S. Lange is funded by a National Institutes of Health grant (K99HL 107744 -0 1). V. Sorrentino is funded by a Telethon grant (GGP08 153B) and PRIN 2009

Submitted: 21 May 2012

Accepted: 24 January 2013

\section{References}

Ackermann, M.A., A.P. Ziman, J. Strong, Y. Zhang, A.K. Hartford, C.W. Ward, W.R. Randall, A. Kontrogianni-Konstantopoulos, and R.J. Bloch. 2011. Integrity of the network sarcoplasmic reticulum in skeletal muscle requires small ankyrin 1. J. Cell Sci. 124:3619-3630. http://dx.doi.org/ $10.1242 /$ jcs.085159

Armani, A., S. Galli, E. Giacomello, P. Bagnato, V. Barone, D. Rossi, and V. Sorrentino. 2006. Molecular interactions with obscurin are involved in the localization of muscle-specific small ankyrin1 isoforms to subcompartments of the sarcoplasmic reticulum. Exp. Cell Res. 312:3546-3558. http://dx.doi.org/10.1016/j.yexcr.2006.07.027

Ayalon, G., J.Q. Davis, P.B. Scotland, and V. Bennett. 2008. An ankyrin-based mechanism for functional organization of dystrophin and dystroglycan. Cell. 135:1189-1200. http://dx.doi.org/10.1016/j.cell.2008.10.018

Ayalon, G., J.D. Hostettler, J. Hoffman, K. Kizhatil, J.Q. Davis, and V. Bennett. 2011. Ankyrin-B interactions with spectrin and dynactin-4 are required for dystrophin-based protection of skeletal muscle from exercise injury. J. Biol. Chem. 286:7370-7378. http://dx.doi.org/10.1074/jbc .M110.187831

Bagnato, P., V. Barone, E. Giacomello, D. Rossi, and V. Sorrentino. 2003. Binding of an ankyrin-1 isoform to obscurin suggests a molecular link between the sarcoplasmic reticulum and myofibrils in striated muscles. J. Cell Biol. 160:245-253. http://dx.doi.org/10.1083/jcb.200208109

Bennett, V., and A.J. Baines. 2001. Spectrin and ankyrin-based pathways: metazoan inventions for integrating cells into tissues. Physiol. Rev. 81: 1353-1392.

Bennett, V., and J. Healy. 2009. Membrane domains based on ankyrin and spectrin associated with cell-cell interactions. Cold Spring Harb. Perspect. Biol. 1:a003012. http://dx.doi.org/10.1101/cshperspect.a003012

Borzok, M.A., D.H. Catino, J.D. Nicholson, A. Kontrogianni-Konstantopoulos, and R.J. Bloch. 2007. Mapping the binding site on small ankyrin 1 for obscurin. J. Biol. Chem. 282:32384-32396. http://dx.doi.org/10.1074/jbc .M704089200

Bowman, A.L., A. Kontrogianni-Konstantopoulos, S.S. Hirsch, S.B. Geisler, H. Gonzalez-Serratos, M.W. Russell, and R.J. Bloch. 2007. Different obscurin isoforms localize to distinct sites at sarcomeres. FEBS Lett. 581:1549-1554. http://dx.doi.org/10.1016/j.febslet.2007.03.011

Bowman, A.L., D.H. Catino, J.C. Strong, W.R. Randall, A. KontrogianniKonstantopoulos, and R.J. Bloch. 2008. The rho-guanine nucleotide exchange factor domain of obscurin regulates assembly of titin at the Z-disk through interactions with Ran binding protein 9. Mol. Biol. Cell. 19:3782-3792. http://dx.doi.org/10.1091/mbc.E08-03-0237

Carlsson, L., J.G. Yu, and L.E. Thornell. 2008. New aspects of obscurin in human striated muscles. Histochem. Cell Biol. 130:91-103. http://dx.doi .org/10.1007/s00418-008-0413-z

Clark, K.A., A.S. McElhinny, M.C. Beckerle, and C.C. Gregorio. 2002. Striated muscle cytoarchitecture: an intricate web of form and function. Annu. Rev. Cell Dev. Biol. 18:637-706. http://dx.doi.org/10.1146/annurev .cellbio.18.012502.105840

Coisy-Quivy, M., O. Touzet, A. Bourret, R.A. Hipskind, J. Mercier, P. Fort, and A. Philips. 2009. TC10 controls human myofibril organization and is activated by the sarcomeric RhoGEF obscurin. J. Cell Sci. 122:947-956. http://dx.doi.org/10.1242/jcs.040121

Crosbie, R.H., J. Heighway, D.P. Venzke, J.C. Lee, and K.P. Campbell. 1997. Sarcospan, the $25-\mathrm{kDa}$ transmembrane component of the dystrophinglycoprotein complex. J. Biol. Chem. 272:31221-31224. http://dx.doi .org/10.1074/jbc.272.50.31221

Cunha, S.R., and P.J. Mohler. 2008. Obscurin targets ankyrin-B and protein phosphatase 2A to the cardiac M-line. J. Biol. Chem. 283:31968-31980. http://dx.doi.org/10.1074/jbc.M806050200

Cunha, S.R., and P.J. Mohler. 2011. Ankyrin-based cellular pathways for cardiac ion channel and transporter targeting and regulation. Semin. Cell Dev. Biol. 22:166-170. http://dx.doi.org/10.1016/j.semcdb.2010.09.013

Cusimano, V., F. Pampinella, E. Giacomello, and V. Sorrentino. 2009. Assembly and dynamics of proteins of the longitudinal and junctional sarcoplasmic reticulum in skeletal muscle cells. Proc. Natl. Acad. Sci. USA. 106:46954700. http://dx.doi.org/10.1073/pnas.0810243106

Danowski, B.A., K. Imanaka-Yoshida, J.M. Sanger, and J.W. Sanger. 1992. Costameres are sites of force transmission to the substratum in adult rat cardiomyocytes. J. Cell Biol. 118:1411-1420. http://dx.doi.org/10 $.1083 /$ jcb.118.6.1411

Ervasti, J.M. 2003. Costameres: the Achilles' heel of Herculean muscle. J. Biol. Chem. 278:13591-13594. http://dx.doi.org/10.1074/jbc.R200021200

Ervasti, J.M., and K.P. Campbell. 1991. Membrane organization of the dystrophin-glycoprotein complex. Cell. 66:1121-1131. http://dx.doi.org/ 10.1016/0092-8674(91)90035-W

Faulkner, J.A. 2003. Terminology for contractions of muscles during shortening, while isometric, and during lengthening. J. Appl. Physiol. 95:455-459.

Ford-Speelman, D.L., J.A. Roche, A.L. Bowman, and R.J. Bloch. 2009. The rhoguanine nucleotide exchange factor domain of obscurin activates rhoA signaling in skeletal muscle. Mol. Biol. Cell. 20:3905-3917. http://dx.doi .org/10.1091/mbc.E08-10-1029

Fukuzawa, A., S. Idowu, and M. Gautel. 2005. Complete human gene structure of obscurin: implications for isoform generation by differential splicing. J. Muscle Res. Cell Motil. 26:427-434. http://dx.doi .org/10.1007/s10974-005-9025-6

Fukuzawa, A., S. Lange, M. Holt, A. Vihola, V. Carmignac, A. Ferreiro, B. Udd, and M. Gautel. 2008. Interactions with titin and myomesin target obscurin and obscurin-like 1 to the M-band: implications for hereditary myopathies. J. Cell Sci. 121:1841-1851. http://dx.doi.org/10.1242/jcs.028019

Gagelin, C., B. Constantin, C. Deprette, M.A. Ludosky, M. Recouvreur, J. Cartaud, C. Cognard, G. Raymond, and E. Kordeli. 2002. Identification of Ank(G107), a muscle-specific ankyrin-G isoform. J. Biol. Chem. 277:12978-12987. http://dx.doi.org/10.1074/jbc.M111299200

Gautel, M. 2011. The sarcomeric cytoskeleton: who picks up the strain? Curr. Opin. Cell Biol. 23:39-46. http://dx.doi.org/10.1016/j.ceb.2010.12.001

Giacomello, E., and V. Sorrentino. 2009. Localization of ank1.5 in the sarcoplasmic reticulum precedes that of SERCA and RyR: relationship with the organization of obscurin in developing sarcomeres. Histochem. Cell Biol. 131:371-382. http://dx.doi.org/10.1007/s00418-008-0534-4

Giannini, G., A. Conti, S. Mammarella, M. Scrobogna, and V. Sorrentino. 1995. The ryanodine receptor/calcium channel genes are widely and differentially expressed in murine brain and peripheral tissues. J. Cell Biol. 128:893-904. http://dx.doi.org/10.1083/jcb.128.5.893

Hijikata, T., A. Nakamura, K. Isokawa, M. Imamura, K. Yuasa, R. Ishikawa, K. Kohama, S. Takeda, and H. Yorifuji. 2008. Plectin 1 links intermediate filaments to costameric sarcolemma through beta-synemin, alphadystrobrevin and actin. J. Cell Sci. 121:2062-2074. http://dx.doi.org/ $10.1242 /$ jcs.021634

Hoffman, E.P., R.H. Brown Jr., and L.M. Kunkel. 1987. Dystrophin: the protein product of the Duchenne muscular dystrophy locus. Cell. 51:919-928. http://dx.doi.org/10.1016/0092-8674(87)90579-4 
Hopitzan, A.A., A.J. Baines, M.A. Ludosky, M. Recouvreur, and E. Kordeli. 2005. Ankyrin-G in skeletal muscle: tissue-specific alternative splicing contributes to the complexity of the sarcolemmal cytoskeleton. Exp. Cell Res. 309:86-98. http://dx.doi.org/10.1016/j.yexcr.2005.04.013

Kontrogianni-Konstantopoulos, A., E.M. Jones, D.B. Van Rossum, and R.J. Bloch. 2003. Obscurin is a ligand for small ankyrin 1 in skeletal muscle. Mol. Biol. Cell. 14:1138-1148. http://dx.doi.org/10.1091/mbc.E0207-0411

Kontrogianni-Konstantopoulos, A., D.H. Catino, J.C. Strong, S. Sutter, A.B. Borisov, D.W. Pumplin, M.W. Russell, and R.J. Bloch. 2006. Obscurin modulates the assembly and organization of sarcomeres and the sarcoplasmic reticulum. FASEB J. 20:2102-2111. http://dx.doi.org/10.1096/ fj.06-5761com

Kontrogianni-Konstantopoulos, A., M.A. Ackermann, A.L. Bowman, S.V. Yap, and R.J. Bloch. 2009. Muscle giants: molecular scaffolds in sarcomerogenesis. Physiol. Rev. 89:1217-1267. http://dx.doi.org/10.1152/ physrev.00017.2009

Lange, S., K. Ouyang, G. Meyer, L. Cui, H. Cheng, R.L. Lieber, and J. Chen. 2009. Obscurin determines the architecture of the longitudinal sarcoplasmic reticulum. J. Cell Sci. 122:2640-2650. http://dx.doi.org/10.1242/ jcs.046193

Lange, S., S. Perera, P. Teh, and J. Chen. 2012. Obscurin and KCTD6 regulate cullin-dependent small ankyrin-1 (sAnk1.5) protein turnover. Mol. Biol. Cell. 23:2490-2504. http://dx.doi.org/10.1091/mbc.E12-01-0052

Legrand, C., E. Giacomello, C. Berthier, B. Allard, V. Sorrentino, and V. Jacquemond. 2008. Spontaneous and voltage-activated $\mathrm{Ca} 2+$ release in adult mouse skeletal muscle fibres expressing the type 3 ryanodine receptor. J. Physiol. 586:441-457. http://dx.doi.org/10.1113/jphysiol .2007 .145862

Lynch, G.S., R.T. Hinkle, J.S. Chamberlain, S.V. Brooks, and J.A. Faulkner. 2001a. Force and power output of fast and slow skeletal muscles from mdx mice 6-28 months old. J. Physiol. 535:591-600. http://dx.doi.org/ 10.1111/j.1469-7793.2001.00591.x

Lynch, G.S., R.T. Hinkle, and J.A. Faulkner. 2001b. Force and power output of diaphragm muscle strips from $\mathrm{mdx}$ and control mice after clenbuterol treatment. Neuromuscul. Disord. 11:192-196. http://dx.doi.org/ 10.1016/S0960-8966(00)00170-X

Maiweilidan, Y., I. Klauza, and E. Kordeli. 2011. Novel interactions of ankyrins$\mathrm{G}$ at the costameres: the muscle-specific Obscurin/Titin-Binding-related Domain (OTBD) binds plectin and filamin C. Exp. Cell Res. 317:724736. http://dx.doi.org/10.1016/j.yexcr.2011.01.002

Mathur, S., R.S. Vohra, S.A. Germain, S. Forbes, N.D. Bryant, K. Vandenborne, and G.A. Walter. 2011. Changes in muscle T2 and tissue damage after downhill running in mdx mice. Muscle Nerve. 43:878-886. http://dx.doi .org/10.1002/mus.21986

Michele, D.E., R. Barresi, M. Kanagawa, F. Saito, R.D. Cohn, J.S. Satz, J. Dollar, I. Nishino, R.I. Kelley, H. Somer, et al. 2002. Post-translational disruption of dystroglycan-ligand interactions in congenital muscular dystrophies. Nature. 418:417-422. http://dx.doi.org/10.1038/nature00837

Mohler, P.J., W. Yoon, and V. Bennett. 2004. Ankyrin-B targets beta2-spectrin to an intracellular compartment in neonatal cardiomyocytes. J. Biol. Chem. 279:40185-40193. http://dx.doi.org/10.1074/jbc.M406018200

Mohler, P.J., J.Q. Davis, and V. Bennett. 2005. Ankyrin-B coordinates the $\mathrm{Na} / \mathrm{K}$ ATPase, $\mathrm{Na} / \mathrm{Ca}$ exchanger, and InsP3 receptor in a cardiac T-tubule/ SR microdomain. PLoS Biol. 3:e423. http://dx.doi.org/10.1371/journal .pbio.0030423

Nelson, W.J., and E. Lazarides. 1983. Switching of subunit composition of muscle spectrin during myogenesis in vitro. Nature. 304:364-368. http:// dx.doi.org/10.1038/304364a0

Pardo, J.V., J.D. Siliciano, and S.W. Craig. 1983. Vinculin is a component of an extensive network of myofibril-sarcolemma attachment regions in cardiac muscle fibers. J. Cell Biol. 97:1081-1088. http://dx.doi.org/ 10.1083/jcb.97.4.1081

Petrof, B.J., J.B. Shrager, H.H. Stedman, A.M. Kelly, and H.L. Sweeney. 1993. Dystrophin protects the sarcolemma from stresses developed during muscle contraction. Proc. Natl. Acad. Sci. USA. 90:3710-3714. http://dx.doi .org/10.1073/pnas.90.8.3710

Pfuhl, M., and M. Gautel. 2012. Structure, interactions and function of the $\mathrm{N}$-terminus of cardiac myosin binding protein $\mathrm{C}$ (MyBP-C): who does what, with what, and to whom? J. Muscle Res. Cell Motil. 33:83-94. http://dx.doi.org/10.1007/s10974-012-9291-z

Porter, G.A., G.M. Dmytrenko, J.C. Winkelmann, and R.J. Bloch. 1992. Dystrophin colocalizes with $\beta$-spectrin in distinct subsarcolemmal domains in mammalian skeletal muscle. J. Cell Biol. 117:997-1005. http:// dx.doi.org/10.1083/jcb.117.5.997

Prins, K.W., D.A. Lowe, and J.M. Ervasti. 2008. Skeletal muscle-specific ablation of gamma(cyto)-actin does not exacerbate the mdx phenotype. PLoS ONE. 3:e2419. http://dx.doi.org/10.1371/journal.pone.0002419
Prins, K.W., J.L. Humston, A. Mehta, V. Tate, E. Ralston, and J.M. Ervasti. 2009. Dystrophin is a microtubule-associated protein. J. Cell Biol. 186:363-369. http://dx.doi.org/10.1083/jcb.200905048

Raeker, M.Ö., and M.W. Russell. 2011. Obscurin depletion impairs organization of skeletal muscle in developing zebrafish embryos. J. Biomed. Biotechnol. 2011:1-15. http://dx.doi.org/10.1155/2011/479135

Rezniczek, G.A., P. Konieczny, B. Nikolic, S. Reipert, D. Schneller, C Abrahamsberg, K.E. Davies, S.J. Winder, and G. Wiche. 2007. Plectin $1 f$ scaffolding at the sarcolemma of dystrophic $(m d x)$ muscle fibers through multiple interactions with $\beta$-dystroglycan. J. Cell Biol. 176:965-977. http://dx.doi.org/10.1083/jcb.200604179

Rossi, D., V. Barone, E. Giacomello, V. Cusimano, and V. Sorrentino. 2008. The sarcoplasmic reticulum: an organized patchwork of specialized domains. Traffic. 9:1044-1049. http://dx.doi.org/10.1111/j.1600-0854 2008.00717.x

Russell, M.W., M.Ö. Raeker, K.A. Korytkowski, and K.J. Sonneman. 2002. Identification, tissue expression and chromosomal localization of human Obscurin-MLCK, a member of the titin and Dbl families of myosin light chain kinases. Gene. 282:237-246. http://dx.doi.org/10.1016/ S0378-1119(01)00795-8

Salanova, M., G. Priori, V. Barone, E. Intravaia, B. Flucher, F. Ciruela, R.A.J. McIlhinney, J.B. Parys, K. Mikoshiba, and V. Sorrentino. 2002. Homer proteins and $\mathrm{InsP}(3)$ receptors co-localise in the longitudinal sarcoplasmic reticulum of skeletal muscle fibres. Cell Calcium. 32:193-200. http:// dx.doi.org/10.1016/S0143416002001549

Serra, F., M. Quarta, M. Canato, L. Toniolo, V. De Arcangelis, A. Trotta, L. Spath, L. Monaco, C. Reggiani, and F. Naro. 2012. Inflammation in muscular dystrophy and the beneficial effects of non-steroidal anti-inflammatory drugs. Muscle Nerve. 46:773-784. http://dx.doi.org/10.1002/mus.23432

Sorrentino, V. 2011. Sarcoplasmic reticulum: structural determinants and protein dynamics. Int. J. Biochem. Cell Biol. 43:1075-1078. http://dx.doi .org/10.1016/j.biocel.2011.04.004

Thompson, T.G., Y.M. Chan, A.A. Hack, M. Brosius, M. Rajala, H.G. Lidov, E.M. McNally, S. Watkins, and L.M. Kunkel. 2000. Filamin 2 (FLN2): A muscle-specific sarcoglycan interacting protein. J. Cell Biol. 148:115126. http://dx.doi.org/10.1083/jcb.148.1.115

Williams, M.W., and R.J. Bloch. 1999. Extensive but coordinated reorganization of the membrane skeleton in myofibers of dystrophic $(m d x)$ mice. $J$. Cell Biol. 144:1259-1270. http://dx.doi.org/10.1083/jcb.144.6.1259

Young, P., E. Ehler, and M. Gautel. 2001. Obscurin, a giant sarcomeric Rho guanine nucleotide exchange factor protein involved in sarcomere assembly. J. Cell Biol. 154:123-136. http://dx.doi.org/10.1083/jcb.200102110

Zhou, D., C.S. Birkenmeier, M.W. Williams, J.J. Sharp, J.E. Barker, and R.J. Bloch. 1997. Small, membrane-bound, alternatively spliced forms of ankyrin 1 associated with the sarcoplasmic reticulum of mammalian skeletal muscle. J. Cell Biol. 136:621-631. http://dx.doi.org/10.1083/jcb.136.3 .621 